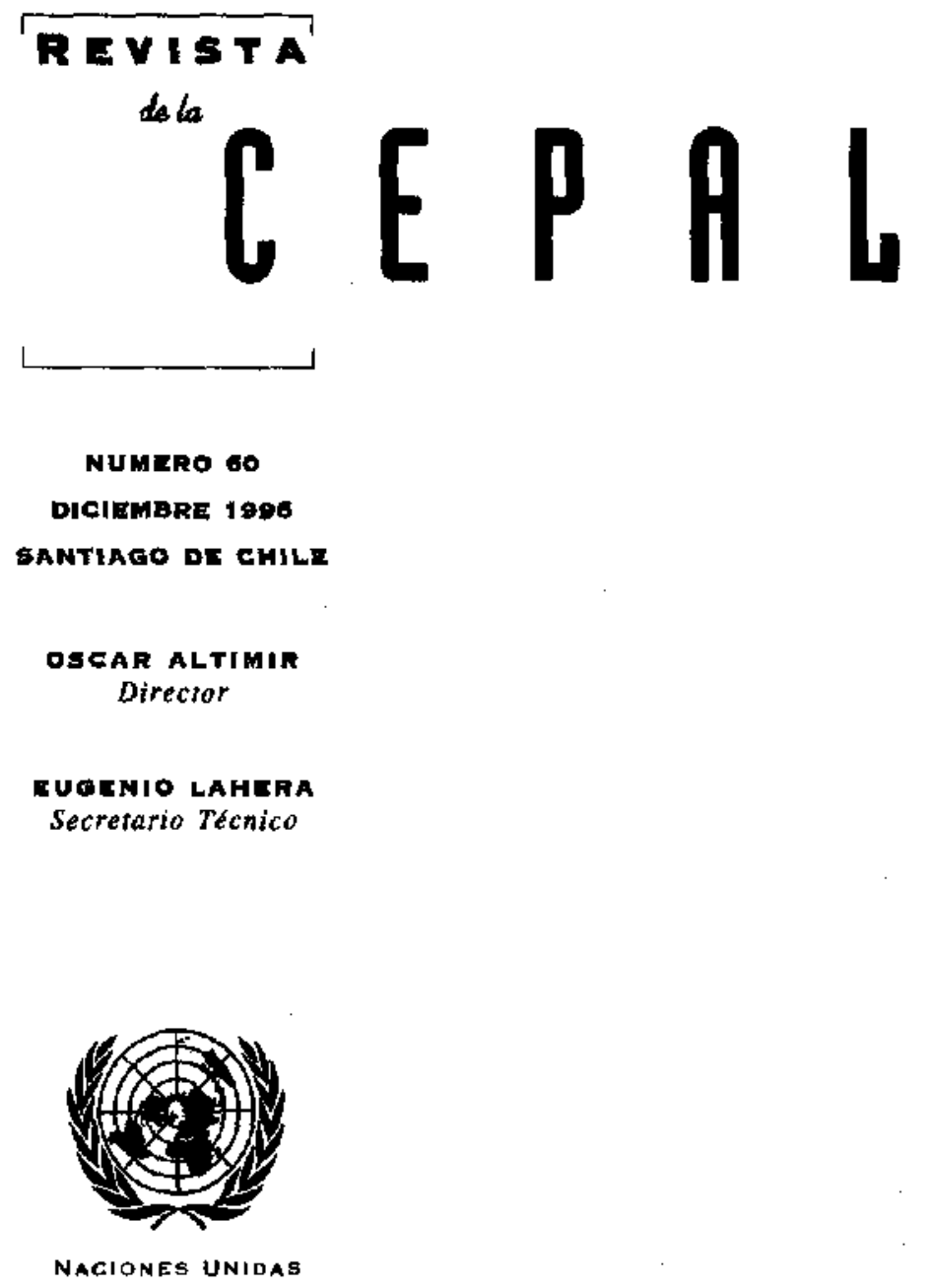


La evolución de las ideas y las políticas para el desarrollo

Gert Rosenthal

Políticas macroeconómicas para el crecimiento

Ricardo Ffrench-Davis

Flujos de capitales: lecciones a partir de la experiencia chilena

Eduardo Aninat, Christian Larrain

La transformación del desarrollo industrial de América Latina

José Miguel Benavente, Gustavo Crespi, Jorge Katz, Giovanni Stumpo

Las reformas de las pensiones en América Latina y la posición de los organismos internacionales

Carmelo Mesa-Lago

Aportes de la antropología aplicada al desarrollo campesino

John Durston

Prospección de la biodiversidad: potencialidades para los países en desarrollo

Julie M. Feinsilver

La inversión extranjera y el desarrollo competitivo en América Latina y el Caribe

Alejandro C. Vera-Vassallo

La crisis del peso mexicano

Stephany Griffith-Jones

Publicaciones recientes de la CEPAL 


\section{La transformación del desarrollo industrial de América Latina}

\section{José Miguel Benavente* Gustavo Crespi* Jorge Katz** Giovannl Stumpo***}

* Universidad de Chile

** División de Desarrollo

Productivo y Empresarial, CEPAL

**** Oficial de Asuntos

Económicos, Divistón de

Desarrollo Empresarial, CEPAL
La liberalización comercial, la desregulación de la actividad económica, la privatización de activos productivos del sector público, así como un manejo mucho más cuidadoso de los grandes agregados macroeconómicos, están causando cambios profundos en el comportamiento de las economías cie América Latina. Un mayor "clima" competitivo se esta difundiendo gradualmente en los diversos países de la región, a medida que las empresas, los mercados y las instituciones se van adaptando a un nuevo escenario micro y macroeconómico. Este artículo analiza las modificaciones de diverso tipo en la estructura productiva de las firmas industriales en América Latina, las variaciones de la productividad, el régimen de incentivos y la organización industrial, así como la organización đel trabajo y los sesgos de los cambios vinculados a los factores productivos. Entre otras conclusiones, se verifica que la industria disminuye constantemente su peso en el PlB, caída que se acelera desde los años ochenta, en el marco de una reorientación de la estructura productiva regional hacia los recursos naturales y los servicios. Por otra parte, también se comprueba que durante el último cuarto de siglo se ha dado un proceso de convergencia de la productividad regional y la de Estados Unidos en los sectores de commodities industriales, en particular en el sector de transportes, y también, aunque en menor medida, en el sector metalmecánico; la brecha de productividad se ha ensanchado, en cambio, en el sector más tradicional (productos textiles, vestuario, calzado y otros), mientras que el sector de alimentos, bebidas y tabaco no ha presentado variación. 
I

\section{Introducción}

La liberalización comercial, la desregulación de la actividad económica, la privatización de activos productivos del sector público, así como también un mucho más cuidadoso manejo de los grandes agregados macroeconómicos, están induciendo cambios profundos en el comportamiento de las economías de Amé rica Latina. En los diversos países de la región se está difundiendo gradualmente un mayor "clima" competitivo, a medida que las empresas, los mercados y las instituciones se van adaptando a un nuevo escenario micro y macroeconómico.

Un perfodo relativamente largo de esfuerzos encaminados a la sustitución de importaciones, en el que las firmas básicamente respondían a señales provenientes del mercado interno, parece estar llegando a su fin.

Los economistas neoclásicos han descrito de manera bastante peyorativa lo alcanzado por los parses latinoamericanos durante el proceso sustitutivo, así como también el papel que desempenaron las políticas industriales en las décadas de posguerra. Para ellos, la intervención activa de los gobiernos en el campo de la producción manufacturera sólo fue capaz de lograr el montaje de plantas industriales ineficientes y de subsidiar a empresarios rentistas, incapaces de competir en mercados internacionales crecientemente competitivos.

Nosotros pensamos, por el contrario, que los resultados obtenidos durante los años de industrialización sustitutiva no fueron todo lo negativos que la literatura ortodoxa sugiere. En nuestra opinión, el proceso sustitutivo desencadenó la creación y difusión de un gran número de instituciones de crucial importancia para el desarrollo del capitalismo. La expansion industrial indujo la gradual aparición y consolidación de una sofisticada cultura industrial (química, electrica, mecánica, etc.), así como también la acumulación de un vasto arsenal de capacidades tecnologicas internas. Junto con ampliarse la producción manufacturera, muchas firmas industriales y ramas completas de actividad fueron generando un acervo importante de tecnologías y saberes propios, lo que les permitió elevar su productividad laboral y su competitividad internacional, acortando la distancia que las separaba de la frontera tecnologica internacional y ganando participacion en distintos mercados mundiales.
Debemos admitir, sin embargo, que el proceso de maduración descrito no tuvo la magnitud y profundidad del que es dable observar en algunos de los parses del Sudeste asiático, pese a que sin duda tiene muchos más rasgos positivos que lo que los autores más ortodoxos de la profesión han logrado admitir hasta ahora.

Cualquiera sea el juicio que nos merezca la etapa sustitutiva, debemos reconocer que muchas de sus instituciones y gran parte de la agenda de políticas públicas asociadas a ellas - como, por ejemplo, el uso de aranceles aduaneros para estimular la construcción de plantas fabriles o aun el desarrollo de ramas enteras de la industria - han sido en la actualidad abandonadas por los gobiernos de América Latina; éstos se han ido volcando hacia los nuevos principios doctrinarios dc la liberalización economica y la desregulación y privatización de la actividad productiva, en la expectativa de que la 'mano invisible' del mercado estará en condiciones de lograr un más rápido ritmo de modernización y cambio tecnológico que el alcanzado durante la sustitución de importaciones bajo la dirección del Estado.

Las firmas industriales han comenzado gradualmente a reaccionar a estos cambios en su escenario operacional. 'Viejas' formas de organización de la producción -que involucraban, por ejemplo, extensos inventarios de partes y piezas o un alto grado de integración vertical- han comenzado a ser dejadas de lado por los empresarios a medida que aprenden a utilizar -y adaptan a sus propias necesidades y circunstancias- los principios organizacionales de la manufactura 'flexible' y los métodos de 'justo a tiempo' y 'cero defecto'. Una mayor subcontratación de insumos intermedios y de servicios a la producción, así como también un más alto contenido unitario de importaciones en sus respectivos programas de trabajo, aparecen hoy como estrategias corrientes dentro de la vida empresaria.

La turbulencia de los años ochenta es ahora un hecho del pasado y la región está gradualmente aprendiendo a vivir con la liberalización comercial y la desregulación de la actividad productiva. Esta transición abre sin duda muchos nuevos interrogantes, como los siguientes: ¿Es hoy la estructura productiva de la región en algún sentido diferente de la que observába- 
mos, digamos, diez o quince antos attás, y si Jo es, en qué sentido? ¿Podemos esperar que el nuevo modelo de organización social de la producción se comporte mejor, o peor, en términos de productividad de factores, que el modelo sustitutivo? ¿Qué impacto probable tendrá el cambio en el régimen global de incentivos sobre los distintos países de America Latina? ¿Cuáles son los nuevos escenarios de organización industrial que están tomando forma en los diversos países, y cómo están adaptándose a las nuevas reglas del juego los distintos agentes de la producción (empresas transnacionales, empresas pequeñas y medianas, de origen familiar, grandes conglomerados de capital nacional)? ¿Quế cambios podemos observar en la organización del trabajo y en el planeamiento de la producción a nivel de empresas individuales? ¿Son estos cambios neutrales respecto de los distintos factores o tenemos razones para sospechar que los mismos tienen sesgos hacia el ahorro relativo de capital o de trabajo? ¿Que lecciones podemos sacar de lo que está ccurriendo en la región que sea de utilidad para otros países del mundo que están viviendo un proceso desregulatorio y tecnológico parecido, como los ex países socialistas?

Algunos de estos temas y otros afines se examinarán a lo largo de este artículo. Debemos comenzar, sin embargo, por reconocer que la profesión aún carece de una teorla del crecimiento económico que nos brinde las bases conceptuales para embarcarnos en una exploración de esta índole. El modelo neoclásico convencional está basado en una serie de supuestos simplificadores relacionados con el comportamiento del 'agente representativo' y con las conductas de crecimiento en equilibrio que le impiden integrar de manera realmente útil lo micro con lo macro de una determinada 'historia evolutiva' nacional.

Cuando la estructura productiva, los mercados y la trama institucional de una determinada sociedad atraviesan por un extenso período de turbulencia y miles de empresas cierran sus puertas (7 000 en Chile en los años ochenta, más de 20000 en Argentina), a la vez que muchos mercados desaparecen o se tornan menos 'profundos' $y$ las instituciones sufren una metamorfosis dramática en sus fines y medios, no podemos simplemente suponer que una vez que la turbulencia acaba la misma estructura productiva seguirá en pie y se volverá a un sendero de crecimiento con equilibrio de largo plazo en el cual los 'rasgos estilizados' centrales del modelo serán sólo marginalmente distintos de los vigentes antes del episodio descrito.

En una situación de este tipo emergen muchas nuevas firmas, industrias e instituciones, en tanto que otras declinan o lisa y llanamente desaparecen. Los mercados de capital y trabajo cambian en su estructura, comportamiento e instituciones prototípicas. Diferentes formas de organización de la producción comienzan a ser utilizadas por las empresas, y una nueva combinación de lo público y lo privado emerge en cuanto a ahorro e inversion y a financiamiento y provisión de 'bienes públicos' (como salud, educación y otros). Este proceso involucra una modificación de lo que los economistas franceses han dado en denominar el 'modo de regulación' de sociedad. Nos parece evidente que en una transicion de este tipo entre 'regímenes regulatorios' simplemente carecemos de información sobre lo que está pasando y nos falta comprensión sobre la naturaleza última del proceso y los nuevos comportamientos microeconómicos emergentes, lo que hace necesario - y hasta urgente- encarar nueva investigacion micro y mesoeconómica que nos permita iluminar los problemas y oportunidades que la nueva situación pone al descubierto. El propósito de este trabajo es justamente el de iniciar una exploración de este tipo, entendiendo que en cl futuro será neccsaria mucha más investigación básica si hemos de describir adecuadamente el nuevo escenario de organización social de la producción que se gesta actualmente en América Latina.

En lo que a la región concierne, un primer hecho parece claro. A pesar de que los esfuerzos de apertura, destegulación y privatización de la actividad productiva son en algún sentido parecidos entre países, los cambios han ido ocurriendo en ellos de maneras y a ritmos muy diferentes. También observamos una gran variedad en sus resultados, porque los tiempos, secuencias y profundidad de las medidas de liberalización comercial y de desregulación econónica han sido muy diversos, como también lo han sido el apoyo político interno y el respalde financiero externo que cada país ha conseguido para su programa de reforma estructural. Por otro lado, las medidas de estabilización macroeconómica y reforma estructural están siendo aplicadas por sociedades que difieren profundamente en su grado de madurez economica, en sus instituciones y en el cuadro de organización social de la producción. Poco puede sorprender en este contexto la diversidad de resultados.

La profesión todavía no ticne un modolo o conjunto de modelos capaces de ilustrar adecuadamente algunos de los vínculos micro/macro involucrados en cuestiones de este tipo y mucho menos aún las complejas interdependencias que existen entre la conducta 
de los agentes económicos individuales y los grandes cambios del régimen de políticas públicas, en distintos niveles de maduración socioeconómica. La cosa se complica aun más cuando admitimos la existencia de información imperfecta por parte de dichos agentes, o de mercados incompletos. Simplemente no sabemos cómo deberfan comportarse las diferentes ramas industriales ante cambios en la tasa de interés o el tipo de cambio. Ni cómo los diferentes tipos de empresas -con distinto acceso a los mercados de factores y con diferente percepción de lo que implica el cambio en el régimen regulatorio - habrán de posicionarse ante las nuevas reglas del juego. $Y$, a la inversa, tampoco sabemos mucho acerca de cómo inciden los distintos grados de maduración económica en la sustentabilidad a largo plazo de las medidas de apertura económica y desregulación de la actividad productiva.

En todos estos sentidos verdaderamente carecemos de una teoría sólida que nos dé apoyo en nuestras afirmaciones. Por lo tanto, intentaremos avanzar aquí desde una perspectiva inductiva en lugar de teorizar $a$ priori acerca de lo que está ocurriendo. Presentaremos al lector una 'historia apreciativa', como denomina Nelson (1995) a este tipo de aproximación a la teorización económica desde lo empírico; nos parece útil para encaminar futuros esfuerzos más formales de modelización, sabiendo un poco mejor qué es que lo que necesitamos plantear en un plano formal. Comenzaremos describiendo algunos de los hechos estilizados centrales de la nueva situación que se está consolidando.

\section{II}

\section{Principales rasgos estilizados de la estructura productiva emergente}

En mayor o menor medida, los diversos rasgos estilizados de la estructura productiva que examinaremos en esta sección pueden hallarse en todos y cada uno de los países latinoamericanos. Sin embargo la naturaleza altamente idiosincrática de cada escenario nacional no puede ser olvidada a la hora de discutir el comportamiento de largo plazo de cada economía. Entre los rasgos más sobresalientes de la nueva estructura productiva cabe mencionar los siguientes:

i) La industria manufacturera ha dejado de ser el motor del crecimiento económico, como lo fue durante la etapa sustitutiva. Tampoco es hoy, ni volverá a ser en el futuro, una fuente importante de generación de nuevos empleos. Los recursos naturales, las industrias procesadoras de materias primas y las actividades no transabies con el exterior se han transformado hoy en campos muy importantes de expansion economica y de absorción ocupacional.

ii) Los países están hoy mucho más expuestos que antes a la competencia internacional, tanto por el lado de las importaciones como de las exportaciones, y el sector externo de cada economía desempeña un papel más importante que años atrás. Las exportaciones de las industrias procesadoras de recursos naturales y de alimentos, así como de productos primarios, están creciendo aceleradamente, pero las importaciones de bie- nes de capital y de productos con alto contenido de mano de obra lo hacen a un ritmo aún mayor, tornando crecientemente negativo el balance comercial en materia de manufacturas.

iii) El grado de concentración económica ha aumentado de manera considerable en los años noventa, a medida que un reducido número de grandes conglomerados nacionales y de subsidiarias locales de firmas transnacionales fueron aprovechando mejor las condiciones operativas abiertas por las nuevas políticas públicas y por el nuevo marco regulatorio imperante hoy en los países de la región. Las empresas pequeñas y medianas (PYME) y las empresas públicas han ido perdiendo participación en la producción manufacturera $y$ en el comercio, como resultado de los programas de privatización, las imperfecciones del mercado y la escasa comprensión de los cambios que el modelo de organización productiva necesita para poder sobrevivir en las presentes circunstancias. Estos hechos han afectado particularmente a las PYME.

iv) Solo un pequeño número de países de la región parece haber retornado a un sendero de crecimiento con equilibrio tras las turbulencias macroeconómicas de los años ochenta. El aumento de las tasas de ahoro e inversión y la creación de nueva capacidad instalada parecen haber determinado el crecimiento eco- 
nómico en tales casos. Chile es el ejemplo más claro de este tipo de situación. Otro grupo de países que han dejado atrás esas turbulencias macroeconómicas todavía enfrenta diversos signos de incertidumbre. Su rápida tasa de expansión en el decenio de 1990 se debió más a una mayor utilización de la capacidad instalada y a cambios tecnológicos ahorradores de mano de obra que a nuevas inversiones, como sucedió en Chile. Argentina y Brasil son los dos ejemplos más significativos de esta situación.

v) La productividad laboral media de la región está todavía considerablemente por debajo de los estándares internacionales y los datos disponibles sugieren que la distancia entre una y otros -es decir, la brecha relativa- no se está reduciendo significativamente a través del tiempo.

Si en lugar de mirar a la economía en su conjunto prestamos más atención al sector manufacturero, observamos lo siguiente:

i) Las industrias procesadoras de materias primas -.esto es, aquellas que producen celulosa y papel, productos petroquímicos, hierro y acero, aceites vegetales, aluminio, harina de pescado, minerales, etc.exhiben un crecimiento significativamente superior al de las ramas industriales que hacen uso intensivo de conocimientos tecnologicos y servicios de ingeniería (productoras de equipos de capital, instrumentos electrónicos, industria química fina).

ii) En los años ochenta entró en producción una nueva generación de plantas industriales con alta densidad de capital, de proceso continuo y dedicadas al procesamiento de materias primas y recursos naturales, que han ganado significativa participación tanto en la producción manufacturera total como en las exportaciones industriales de los diversos países de la región.

iii) A diferencia de lo anterior, se observan sig. nos de contracción y decaimiento, así como una alta tasa de mortalidad empresarial, en ramas que hacen uso intensivo de mano de obra (entre otras, las que producen textiles, calzado y vestuario) y también en las que hacen uso relativamente intensivo de servicios de ingenierfa (como las que fabrican máquinas herramientas, calderería pesada, instrumentos, cquipos de uso agrícola, etc. ). En estos sectores las empresas están experimentando grandes dificultades para adaptarse a regímenes competitivos más desregulados y abiertos, así como a nuevas tecnologías con base computacional, prototípicas de la manufactura flexible.

iv) Pese a que la afluencia de inversión extranjera directa decayó significativamente en el curso de los años ochenta, factores como la estabilidad macroeco- nómica y los cambios recientes en el marco de propiedad industrial imperante en los países de la región han desencadenado una nueva ola de inversión manufacturera directa hacia diversos países de América Latina. Las alianzas estratégicas entre grandes conglomerados de capital nacional, las empresas transnacionales, las casas bancarias de escala universal y las firmas consultoras y los contratistas transnacionales han ido aumentando rápidamente en actividades procesadoras de recursos naturales, en la producción de alimentos, la generación y distribución de energía, las telecomunicaciones, el transporte y la explotación de terminales portuarios. La privatización de activos ha ofrecido una amplia gama de oportunidades para dichas alianzas y para el ingreso de nueva inversion extranjera directa.

v) La organización del trabajo a nivel de planta fabril individual y el grado de integración vertical con que las empresas organizan sus programas de producción han ido sufriendo grandes modificaciones como consecuencia de la transición hacia regímenes de producción más abiertos a la competencia externa y de una mayor flexibilidad en los mercados laborales. Es evidente que el alto grado de integración vertical de los años setenta no es rentable hoy, cuando la importación de partes, piezas y subconjuntos se ha abaratado y simpliffcado. En años recientes, muchas empresas productoras de bienes de capital o de bienes de consumo han aumentado significativamente el contenido unitario de importaciones en sus producciones, sustituyendo partes y piezas producidas localmente, o incluso al interior de la empresa, por equivalentes importados. Esto está afectando de manera dramática a sus anteriores proveedores, muchos de ellos pequeñas y medianas empresas de origen familiar involucradas en la producción metalmecánica, entre los cuales la tasa de mortalidad empresaria está siendo anormalmente alta. Las grandes empresas han avanzado hacia la 'desverticalización' de sus procesos productivos, recurriendo a proveedores externos para obtener servicios como los de computación, mantenimiento y otros; simultáneamente, han reducido su compromiso con actividades locales de diseño de productos y procesos productivos y con tareas de investigación y desarrollo, incrementando en cambio su uso de licencias internacionales.

vi) Se observa una significativa diferencia de resultados entre aquellas firmas que hat adoptado una estrategia proactiva de adaptación a las nuevas circunstancias y en función de ello han invertido en nuevos equipos, han capacitado a su personal y han modificado la composición de los bienes ofrecidos al mercado, 
y aquéllas otras que han tenido una actitud defensiva $y$ han introducido cambios organizacionales que ahorran mano de obra, pero sin comprometerse significativamente a través de la expansión de su capacidad instalada.
Hasta aquí una rápida descripción estilizada de varios de los rasgos más salientes de la situación contemporánea. En las próximas dos secciones del trabajo examinaremos la información empírica sobre la cual se apoyan nuestras afirmaciones anteriores.

\section{III}

\section{La economía global y la industria} manufacturera en su conjunto

\section{Rasgos centreles del proceso de reestructura- ción del aparato productivo tras la crisls de la deuda de los afios ochenta}

Los primeros años de la posguerra marcaron una etapa de rápida expansión de la economía latinoamericana. Se recuperó tanto el pivel de actividad económica como la inversión bruta luego del extenso período de restricciones en el acceso a bienes de capital y financiamiento externo que implicó el conflicto bélico. Las dos décadas comprendidas entre los inicios de los años cincuenta y principios de los setenta pueden ser consideradas como la edad de oro del modelo de desarrollo basado en la sustitución de importaciones.

Sin embargo, ya a mediados de los setenta varios países de la región sufrieron una fuerte desaceleración del ritmo de crecimiento del PIB global y del industrial, o de la productividad laboral, planteándoles la necesidad de profundizar o reformular sus estrategias.

Al menor dinamismo que trajo el agotamiento del modelo sustitutivo se agregaron importantes shocks externos adversos. En efecto, las dos crisis del petróleo en los años setenta marcaron el comienzo de grandes turbulencias macroeconómicas en la región, que se acentuaron en los ochenta con la crisis de la deuda, la caída de la relación de precios del intercambio y el alza de las tasas de interés internacionales.

La transformación del contexto macroeconómico tuvo efectos dispares en los distintos países, tanto por su diferente capacidad de absorber las conmociones externas como por las políticas aplicadas en cada caso. Sin embargo, en términos generales, una de las características de la década de 1980 fue, para la región en su conjunto, el recrudecimiento de los procesos inflacionarios, acompañado por políticas de estabilización, primero, y de reforma estructural después, que sin duda afectaron significativamente tanto el ritmo como la naturaleza del proceso de crecimiento. En la segunda mitad del decenio, varios países de la región comenzaron a exhibir signos de una reversión gradual ( $y$ aún bastante débil) de las tendencias negativas. Sin embargo, sólo a partir de los años noventa los indicadores agregados - -PIB total y per cápita, formación bruta de capital fijo, exportaciones e importaciones-reflejaron un más claro proceso de recuperación (cuadro 1).

En términos generales, y pese a las diferencias entre países, las economías de la región han denotado en los af̃os noventa una reorientación notable hacia el exterior y hacia una más intensiva explotación de sus recursos naturales, los que a su vez se han expandido significativamente tanto en cantidad como en calidad. Las exportaciones, que ya entre 1980 y 1990 habian crecido en un $5.4 \%$ anual en términos reales, han tenido en los años noventa tasas de incremento reales muy cercanas al 7\%. Un crecimiento más acentuado aún se ha observado en las importaciones de la región, las que pasaron de tasas de crecimiento medio anual negativas a valores cercanos al 15\% anual en 1990-1994.

CUADRO

América Latina (12 paises): Tasas medias de crecimiento, $1950-1994$ (Porcentajes)

\begin{tabular}{lcccc}
\hline & $1950-1974$ & $1974-1980$ & $1980-1990$ & $1990-1994$ \\
\hline PlB per cápita & 2.4 & 2.6 & -0.8 & 1.9 \\
$\begin{array}{l}\text { Exportaciones } \\
\text { Importaciones }\end{array}$ & 3.9 & 3.5 & 5.4 & 6.6 \\
$\begin{array}{l}\text { Formación bruia } \\
\text { de capital }\end{array}$ & 6.0 & 5.7 & -0.8 & 14.4 \\
\hline
\end{tabular}

Fuente; Elaboración propia sobre la base de datos de la CEPAL. 
CUADRO 2

América Latina: Evolución sectorial del PIE, 1950-1994

(Porcentajes)

\begin{tabular}{lcccc}
\hline & $1950-1974$ & $1974-1980$ & $1980-1990$ & $1990-1994$ \\
\hline Agricultura & 3.5 & 3.7 & 2.2 & 2.4 \\
Minetra & 4.3 & 0.9 & 2.7 & 3.3 \\
Industria & 6.7 & 4.3 & 0.4 & 3.2 \\
Energía & 9.1 & 8.8 & 5.1 & 4.5 \\
Construcción & 5.1 & 5.9 & -2.4 & 5.6 \\
Comercio & 5.9 & 6.0 & 0.2 & 3.7 \\
Transporte & 6.0 & 7.6 & 3.3 & 6.3 \\
Instituciones & & & & \\
financieras & 6.4 & 5.8 & 2.2 & 3.2 \\
Servicios sociales & 6.2 & 5.8 & 2.2 & 1.5 \\
PIB tofal & 5.5 & 5.1 & 1.2 & 3.6 \\
\hline
\end{tabular}

Fuente: Elaboración propia sobre la base de datos de la CEPAL.

No obstante lo anterior, es oportuno subrayar que hasta ahora la recuperación ha sido sólo parcial, dado que las tasas de crecimiento del PIB total y per cápita se encuentran aún muy por debajo de las de los años setenta. La formación bruta de capital fijo representó en 1993 un $18.1 \%$ del PIB, porcentaje inferior no s6́lo al que se logró en 1980, sino también al de 1970.

El perfodo 1950-1994 se caracterizo por fuertes cambios estructurales en la composición del prB regional (cuadro 2), El sector terciario (comercio, transportes, finanzas y servicios sociales) incrementó su participación, mientras que el resto perdió peso relativo. Particularmente importante fue el desempeño del rubro equipos de transporte que creció mucho más que el promedio del PB, mientras que las actividades financieras y de comercio presentaron un dinamismo importante sólo hasta mediados de los años ochenta.

El resto de los sectores, pese a haber tenido comportamientos diversos, perdió peso relativo. Entre los que acrecentaron su participación en el p'B destacó el de energía, que la duplicó entre 1970 y 1994.

Por otro lado, la participación de la industria en el pIB disminuyó constantemente, caída que se acentuó en los afios ochenta. Si bien este proceso se aceleró en los años noventa, ya desde el decenio de 1970 la industria, pese a su elevada tasa de expansión de $4.3 \%$ en 1974-1980, había dejado de constituir el motor principal del crecimiento de la región, y había disminuido levemente su peso relativo.

En la primera mitad del decenio de 1980 el sector industrial entró en una profunda crisis y luego permaneció estancado durante casi 10 años. La recuperación del primer quinquenio de los años noventa fue inferior a la de la economía en su conjunto, confirmán- dose así su tendencia a perder participación dentro de la estructura económica regional.

Por su parte, los sectores primarios (agricultura y minería), luego de experimentar una pérdida sistemática de participación en el PIB, a partir de 1980 comenzaron a crecer a tasas mayores que la economía en su conjunto y elevaron su importancia relativa. Esta situación tendió a revertirse en el periodo 1990-1994, en que el sector primario volvió a crecer a tasas más bajas que la economía en su conjunto.

El comportamiento descrito da una idea de la importancia que ha tenido la caída de la demanda interna agregada —consecuencia de los programas de estabilizacion - como factor determinante de la crisis del sector manufacturero. En efecto, esa baja fue mucho mayor en los sectores (industria, construccion, comercio) donde la elasticidad-ingreso de la producción es más alta. En cambio, el sector primario en su conjunto fue en los años ochenta más dinámico que los otros sectores (inclusive el terciario). En este sentido, podemos afirmar que entre 1980 y 1990 hubo una clara reorientación de la estructura productiva regional hacia los recursos naturales y los servicios.

Los sectores vinculados a los recursos naturales, incluyendo entre ellos tanto la agricultura y la minería como la producción de commodities industriales, tuvieron un rol de particular importancia en el nuevo modelo de inserción internacional de las economías de la región que se configuró a partir de los años setenta (cuadro 3). La expansión de estos sectores de recursos naturales depende tanto del desarrollo de productos 'nuevos' (madera, fruta fresca y pescado en Chile) como del incremento del volumen físico de producción de bienes ya exportados desde décadas anteriores: soya, semilla de girasol y trigo en Argentina; café verde, caña de azúcar y soya en Brasil; carbón y petróleo en CoIombia; cobre en Chile; petróleo en Ecuador; bauxita, estaño, hierro y petróleo en Brasil; carbón y hierro en Venezuela .

Los recursos naturales han sido también un elemento clave en el desarrollo de otros sectores que tuvieron gran importancia para la reestructuración de las economías latinoamericanas en los años ochenta. Nos referimos a las industrias productoras de commodities industriales y a algunos sectores de servicios asociados a ellas. El tema de los commodities industriales será examinado en las páginas siguientes. Respecto a los servicios conexos, podemos decir que, en alguna medida, las grandes exigencias de infraestructura vial, portuaria y de comunicaciones vinculadas a la producción de bienes primarios y de commodities industria- 
Amorlca Latina: Producción te algunos blenes agricolas y mineros, 1970-1983 (Miles de toneladas)

\begin{tabular}{|c|c|c|c|c|c|}
\hline & 1970 & 1980 & 1985 & 1990 & 1993 \\
\hline Banano y plátano & 20564 & 21 671 & 22270 & 26939 & 27637 \\
\hline Café verde & 2170 & 2970 & 3839 & 3883 & 3629 \\
\hline Caña de azúcar & 277943 & 356626 & 457703 & 490370 & 454234 \\
\hline Girasol & 1220 & 1756 & 3522 & 4035 & 3432 \\
\hline Marz & 38095 & 45280 & 55771 & 50067 & 67999 \\
\hline Soya & 1927 & 19814 & 27. 167 & 34325 & 36463 \\
\hline Trigo & 11509 & 14874 & 20215 & 20922 & 17295 \\
\hline Producción pecuaria & 76 & 100 & 107 & 123 & 132 \\
\hline Bauxita & 24045 & 24596 & 18029 & 29071 & 33739 \\
\hline Carbón & 10015 & 17626 & 28283 & 34730 & 34064 \\
\hline Cobre & 987 & 1654 & 1961 & 2237 & 2785 \\
\hline Estaño & 35588 & 36167 & 47307 & 61900 & 55600 \\
\hline Hierro & 88355 & 137647 & 149952 & 187254 & 187934 \\
\hline Petroleo & 305603 & 334219 & 367265 & 395506 & 428855 \\
\hline
\end{tabular}

Fuente: CEPAL.

a Producción pecuaria: índice base $1980=100$

les contribuyeron a que el sector "Transporte, almacenamiento y comunicaciones" mantuviera, después del fuerte crecimiento que experimentó en los años setenta, tasas de crecimiento que de 1980 en adelante doblaron con creces las del promedio del PIB.

De la misma manera, el sector "Electricidad, gas y agua", que ya había crecido fuertemente entre 1970 y 1980 , siguío siendo uno de los más dinámicos de la economia regional, gracias a las necesidades de energia de las nuevas producciones basadas en recursos naturales, así como al descubrimiento de nuevas fuentes energéticas.

En resumen, el análisis de la evolución de la economía latinoamericana a partir de 1970 muestra que en el primer lustro de los años setenta concluyó una larga fase de crecimiento; que en los años ochenta se experiment 6 un fuerte proceso contractivo; y que sólo en los años noventa comenzaron a aparecer indicios de cierta recuperación del ritmo de crecimiento.

A lo largo de este proceso de caída y reactivación parcial del nivel de actividad, la estructura económica sufríó modificaciones importantes. La industria dejó de tener un rol protagónico en el proceso de crecimiento, mientras que el sector primario y el de servicios mostraron un mayor dinamismo, el primero a partir de los años ochenta y el segundo desde los setenta.

Junto con marcar un nuevo énfasis en los recursos naturales, el cambio en la estructura econónica reorientó fuertemente la producción hacia el mercado externo, lo que se ha manifestado en un aumento constante y significativo de la relación entre las exportaciones y el PIB desde 1980 en adelante.
En este nuevo panorama que nos presenta hoy la región aparecen también otros elementos menos positivos; ellos plantean desaffos que es necesario entrentar si se quiere garantizar la sustentabilidad del proceso de apertura externa y de desregulación económica. En primer lugar, las importaciones, que habían caído fuertemente entre 1980 y 1985 tanto en valor como en volumen, subieron de ahí en adelante a tasas bastante superiores a las que exhibieron las exportaciones. Por lo tanto, el balance comercial que babía sido claramente positivo en 1985 y 1990 , se volvió negativo (en valores corrientes) en 1993. Como ejemplos particularmente relevantes citaremos el caso de México, pero también los de Argentina y Colombia.'

En segundo lugar, la expansión de la frontera de recursos naturales conlleva un aumento de la presión sobre el medio ambiente. El modelo de crecimiento basado en la explotación más intensiva de recursos naturales sin duda habrá de requerir un mayor cuidado del equilibrio ambiental y, por ende, una más rápida difusion de las normas internacionales relacionadas con el medio ambiente (ISO 14000, eco label, etc.), y nuevos comportamientos institucionales para manejar estos temas.

En tercer lugar, pese a tasas de crecimiento de las exportaciones que en volumen físico son de casi $7 \%$

\footnotetext{
1 Desde este punto de vista los resultados de 1994 fueron aún peores para los parses mencionados y en general para la región. Además, a partir đel último trimestre de 1994 se deterioro notablemente la situacion de Brasil, pais que habia sido ampliamente superavitario desde mediados de los años ochenta.
} 
anual, el PJB per cápita está aumentando sólo $1.9 \%$ por año, lo que crea ciertas dudas acerca del significado último de estrategias lideradas por la exportación como son muchas de las que en años recientes se han aceptado de manera acrítica en el debate económico regional.

\section{Estructura y comportamlento del sector industrial}

a) Las diferentes etapas del proceso de reestructuración

En 1974-1994 la industria latinoamericana pasó por diferentes etapas a lo largo de las cuales se modific 6 profundamente su ritmo de crecimiento, su estructura y las características de su insercion internacional.

Como vimos más atrás, en la segunda mitad de los años setenta la tasa de crecimiento industrial de la región en su conjunto se redujo en forma significativa (cuadro 4), alcanzando un valor más bajo que en los años cincuenta y sesenta. El promedio, de cualquier manera, esconde profundas diferencias entre países. Por un lado la inusustria manufacturera en Argentina, Chile y Perú mostró los primeros signos de estancamiento ya en los años setenta; por otro, la expansión industrial se mantuvo a lo largo de la década en Brasil, Ecuador, Guatemala y México.

Frente a un déficit comercial externo cada vez mayor y una demanda interna menos dinámica, muchos países de la región empezaron a emplear políticas de fomento de las exportaciones en la segunda mitad de

CUADRO 4

América Latina (12 países): Tasas medlas anuales de crecimiento del valor agregado industrial, 1950-1994

\begin{tabular}{lcccc}
\hline & $1950+1974$ & $1974-1980$ & $1980 \cdot 1990$ & $1990-1994$ \\
\hline Argentina & 4.9 & -0.6 & -1.4 & 6.9 \\
Bolivia & 3.7 & 3.4 & -0.6 & 3.3 \\
Brasil & 8.7 & 6.7 & -0.2 & 2.8 \\
Chile & 4.4 & 1.2 & 2.6 & 6.3 \\
Colombia & 6.7 & 4.0 & 2.9 & 3.9 \\
Costa Rica & 8.7 & 5.5 & 3.8 & 5.7 \\
Ecuador & 6.2 & 10.2 & -0.8 & 5.7 \\
Guatemala & 6.1 & 6.1 & -0.1 & 2.8 \\
México & 7.4 & 6.2 & 2.0 & 2.3 \\
Perú & 7.0 & 1.8 & -1.9 & 5.6 \\
Uruguay & 2.4 & 4.9 & -1.0 & -1.3 \\
Venezvela & 7.8 & 5.0 & 1.9 & 1.8 \\
Totat & 6.8 & 4.6 & 0.4 & 3.4 \\
\hline
\end{tabular}

Fuente: Programa de Análisis de la Dinámica Industrial (PADI) y elaboración propia. El PADJ es un programa computacional elaborado por la División de Desarrollo Productivo y Empresarial de la CEPAL para describir y analizar el comportamiento de las principales variables industriales de la región.
CUADRO 5

America Latina: Exportaciones e importaciones Industriales, 1974-1994 (Valores en millones de dólares corrientes)

\begin{tabular}{lrrrr}
\hline & 1974 & 1980 & 1990 & 1994 \\
\hline Exportaciones & 19262 & 41894 & 70407 & 123442 \\
Impottaciones & 28476 & 67284 & 70758 & 163315 \\
Balance comercial & -9214 & -25390 & -351 & -39873 \\
\hline
\end{tabular}

Fuente: Programa de Anólisis de la Dinámica Industrial (PRDI) y elaboración propia.

los años setenta, las que indujeron a las empresas locales a orientarse en forma creciente hacia el mercado externo.

Las exportaciones industriales crecieron de 19262 millones de dólares a 41894 millones entre 1974 y 1980. Sin embargo, el incremento de las importaciones fue aún más rápido, llevando a un deterioro del balance comercial de la región (cuadro 5).

A partir de 1980, y durante toda la década, la producción industrial entró en una fase de claro estancamiento en el conjunto de la region, y de fuerte contracción en algunos países, como Argentina, Uruguay y Perú. En muchos casos el nivel de producción alcanzado en 1990 fue inferior al de 1980.

Con la caída de la demanda interna, el sector externo se transformó en el componente más dinámico de la demanda. Reaccionando a las circunstancias, muchas empresas reorientaron su producción tacia los mercados internacionales y las exportaciones industriales se expandieron rápidamente, pasando de 41894 millones de dólares en 1980 a 70407 millones en 1990. Sin embargo, esta vez las importaciones no se comportaton como en los setenta. Dado que las tasas de crecimiento de la economía fueron mucho menores, las importaciones se incrementaron levemente y se redujo de forma consistente el déficit comercial.

Sin embargo, esta mejor situación externa se dio en un contexto de fuertes cambios internos y externos que impidieron mantenerla por mucho tiempo. Tres aspectos destacan en las nuevas circunstancias: i) las políticas de estabilización macroeconómicas llevaron a fuertes caídas de la demanda interna; ii) la crisis de la deuda externa (reforzada por el alza consiguiente de las tasas de interés y la fuerte reducción del financiamiento externo) deterioró notablemente la situación macroeconómica de la tegión, y iii) el fuerte desplazamiento de la frontera tecnológica internacional (a partir de! descubrimiento y rápida difusión de nuevos productos y procesos productivos basados en micropro- 
cesadores y en el control numérico) ensanchó significativamente la distancia tecnológica entre las prácticas productivas de la región y las mejores prácticas internacionales.

En este marco, el sector industrial sufrío una profunda crisis estructural. La demanda interna se contrajo y la competitividad internacional de muchas empresas y ramas se deterioró con rapidez. Las tasas de crecimiento del sector fueron negativas en la primera mitad de los años ochenta. Miles de empresas dejaron de existir durante esos años y el desempleo alcanzó niveles antes desconocidos en la region. S6lo a fines del decenio esta situación empezo a revertirse y el aparato industrial volvió a crecer. Pero esta vez la expansión se dio con una estructura de producción profundamente modificada y con un modelo de organización productiva muy diferente del que había prevalecido en los años cincuenta y sesenta (sobre este tema volveremos más adelante).

La primera mitad de los años noventa trajo una recuperación parcial del ritmo de incremento de la producción industrial, que para el conjunto de la región fue en promedio de $3.4 \%$ anual entre 1990 y 1994. Este valor, claramente más alto que el del decenio anterior, siguio siendo inferior al $4.6 \%$ del período 1974-1980. En efecto, con la notable excepción de Argentina, Chile, Perú y en menor medida Costa Rica, los países de la region, en su gran mayorá, crecieron mucho menos que en la segunda mitad de los años setenta.

Las exportaciones continuaron incrementándose, pero esta vez los aumentos de la demanda interna y la revaluación de las monedas nacionales en varios países de la región llevaron a incrementos apreciables de las importaciones y a un fuerte deficit en el balance de comercio del sector industrial. La recuperación parcial de la producción fue acompañada por fuertes aumentos de la productividad laboral $(8.0 \%$ anual para el conjunto de la región entre 1990 y 1993). La cifra había sido de $1.6 \%$ en $1974-1980$ y de $1.0 \%$ en 1980-1990.

Es importante señalar, sin embargo, que este mejoramiento de la productividad laboral se logró sin grandes nuevas inversiones (con la excepción de Chile) en la mayoría de los sectores industriales. En general se debió a drásticas reducciones del empleo a raíz de crecientes cambios tecnológicos organizacionales de carácter 'desincorporado'. ${ }^{2}$ En otras palabras, salvo en

\footnotetext{
${ }^{2}$ Es decir, que no vienen asociados a nuevas inversiones físicas.
}

el caso chileno, el incremento de la productividad laboral en la primera mitad de los años noventa ha estado asociado a una fuerte expulsión de mano de obra desde el sector industrial. Mientras que la ocupación industrial habia aumentado hasta 1980 y en los años ochenta se había reducido ligeramente, cayó en un $4.7 \%$ anual entre 1990 y 1993.

En términos absolutos, el nivel alcanzado por la ocupacion en 1993 fue ligeramente inferior al de 1974 , pero en el mismo período la producción se incrementó en un $50 \%$.

En definitiva, la situación del sector industrial a mediados de los años noventa, ya superado el impacto de las políticas de estabilización macroeconómica y liberalización comercial aplicadas entre fines de los años setenta y comienzos de los ochenta, se caracteriza por una renovada capacidad de crecimiento en un número cada vez mayor de países y por fuertes incrementos de la productividad laboral y de la capacidad exportadora.

Frente a ello, las importaciones industriales siguen expandiéndose con rapidez y generando un balance comercial cada vez más negativo para el sector manufacturero, sobre todo en los sectores metalmecánico, electrónico y de bienes de capital, cuyas importacio nes aumentaron espectacularmente después de la libe. ralización comercial.

Otro aspecto significativo, por último, es la muy reducida capacidad del sector industrial para abserber mano de obra.

\section{b) Restructuración de la producción manufacture.} ra y aumento relativo de las industrias procesadoras de recursos naturales

El análisis del desarrollo industrial de los principales países de la region en 1974-1994 muestra un avance relativo de las industrias procesadoras de recursos naturales, junto con una reducción de las ramas de bienes de capital y de bienes de consumo durables (cuadro 6). La composición del valor agregado industrial en 1974 reflejaba un patrón de especialización basado en las ramas del complejo metalmecánico (éste incluye un conjunto de sectores que producen vehículos automotores, bienes de capital y bienes de consumo duraderos, equipos para la agricultura, etc.). Se trata de industrias que hacen uso intensivo de ingenierfa de diseño, así como de mano de obra calificada en la producción y ensamblaje de partes y piezas.

En los dos países tecnológicamente más avanzados de la región (Argentina y Brasil), esos sectores representaban en 1974 alrededor del $30 \%$ del valor de 


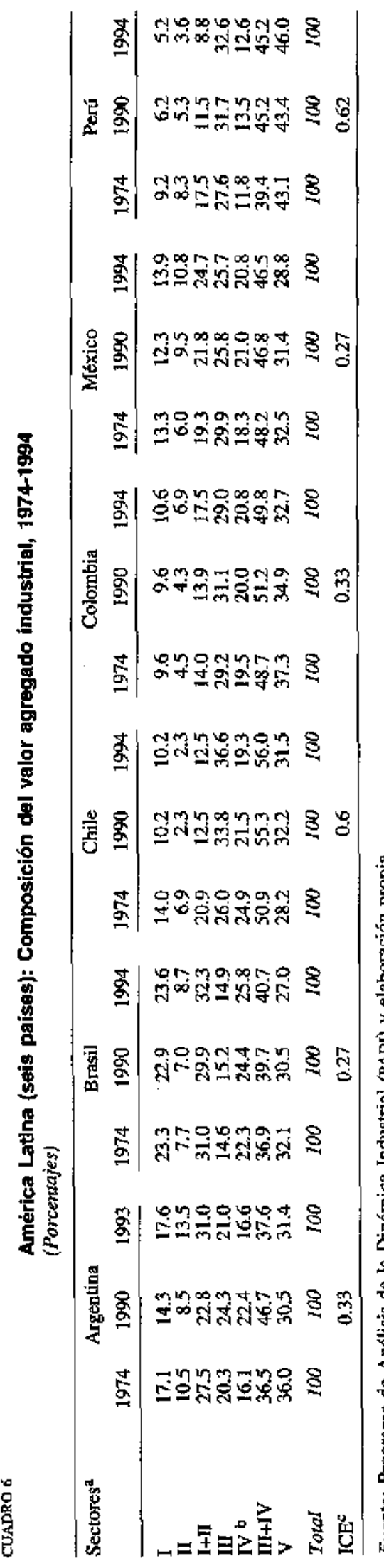

la producción industrial, mientras que en varios otros países (Chile, Méxjco y Perú), donde el tejido industrial no habra alcanzado aún igual nivel de complejidad, el complejo metalmecánico originaba entre 17 y $21 \%$ del valor agregado manufacturero.

Es importante subrayar el alto grado de idiosincrasia con que se desarrollo el sector metalmecánico en las primeras etapas del proceso de sustitución de importaciones.

Pastiendo de capacidades tecnológicas internas bastante magras, muchas pequeñas empresas de carácter familiar lograron expandirse gradualmente, copiando diseños de productos extranjeros anticuados, realizando 'ingeniería reversa' y abasteciéndose con piezas y partes construidas por ellas mismas. Al mismo tiempo, fueron acumulando habilidades ingenieriles y destrezas tecnológicas de tipo 'desincorporado' que complementaban la evolución gradual de su maquinaria y equipo.

A nivel más general, este proceso signifić é 1 desarrollo acumulativo en la región de una 'cultura' industrial antes inexistente, y requirió la absorción y difusión de prácticas, estándares de calidad, límites de tolerancia, normas de subcontratación, etc., que las empresas locales no estaban acostumbradas a utilizar.

Sin embargo, ese modelo de organización industrial presentaba también muchas debilidades que complicarían notablemente su capacidad competitiva de largo plazo en un contexto de apertura de la economía: entre otras, escalas de planta inadecuadas, alto grado de integración vertical, naturaleza ad hoc y muchas veces artesanal de las instalaciones productivas o talleres fabriles, e imperfecta información tecnológica de los empresarios locates. Esto fue particularmente notorio hacia fines de los años setenta, cuando comenz6 a difundirse rápidamente en el mundo una nueva generación de productos y procesos productivos asociados al comando numérico, la informática y los principios de la 'manufactura flexible', los que llegaron con varios años de retraso al escenario latinoamericano.

El rezago tecnológico de las empresas metalmecánicas de América Latina aumentó notablemente en pocos años, haciéndoles más difícil sostener su posición competitiva. La liberalización comercial agravó aún más la situación.

Lo dicho hasta ahora sugiere que, a pesar de que muchas empresas y sectores lograron impertantes aumentos de la productividad y acumularon apreciables conocimientos tecnológicos en la etapa de industrialización sustitutiva de las importaciones, también es 
cierto que los países latinoamericanos no han logrado cerrar la distancia -0 brecha- que los separa de la frontera tecnologica internacional.

Esa distancia se redujo un poco en el período más exitoso de la industrialización (los afios sesenta y la primera mitad de los setenta), pero empezó a ampliarse de nuevo cuando la frontera tecnológica se desplazó hacia productos y procesos controlados numéricamente. Esto se dio particularmente en los sectores metalmecánicos, con la difusión a nivel internacional de una nueva generación de productos y procesos más sofisticados desde fines de los años setenta.

En este contexto, países como Argentina, Brasil, México o Colombia decidieron avanzar en el proceso de industrialización, introduciendo subsidios fiscales a la expansión y profundización del desarrollo de los sectores que procesan recursos naturales, algunos de los cuales se habian establecido en los años cincuenta y sesenta pero requerían una significativa modernización y expansión a fines de los años setenta y en los ochenta. Con estos subsidios fiscales surgió una nueva generación de plantas fabriles caracterizadas por el uso intensivo de capital y por la utilización de tecnologías similares a las más avanzadas tanto en la industria petroquímica como en la produccion de aluminio, celulosa y papel, acero, aceites vegetales y otros bienes. Se entró así en lo que se ha dado en llarnar la 'segunda fase' de la sustitución de importaciones, que incluyó un proceso de 'profundización' del capital, tanto en términos de los sectores escogidos para la expansión como en términos de las tecnologías de producción utilizadas.

En el caso de Chile, en cambio, la expansion de estas ramas productivas no se debí́ a estímulos de carácter ortodoxo, aun cuando es innegable que hubo subsidios, por ejemplo, para la expansión de la base forestal que permitió el posterior desarrollo de las plantas exportadoras de celulosa y papel. En este caso, la transición hacia las industrias procesadoras de recursos naturales fue respuesta a la política de apertura externa y de liberalización económica que el pass aplica desde mediados de los años setenta.

Como resultado de la orientación señalada del crecimiento industrial, el peso de los sectores de alimentos y commodities industriales en la producción manufacturera total creció, entre 1974 y 1990, de 36.5 a $46.7 \%$ en Argentina, de 36.9 a $39.7 \%$ en Brasil, de $39.4 \%$ a $45.2 \%$ en Perú, de $48.7 \%$ a $51.2 \%$ en Colombia y de 50.9 a $55.3 \%$ en Chile. También en México, donde el peso de los sectores de alimentos, bebidas y tabaco es menor, la participación de los commodities industriales subió de 18.3 a $21.0 \%$.
Se redujo, en cambio, la importancia relativa del complejo metalmecánico. En algunos casos (en Chile, por ejemplo) la contracción asumio dimensiones dramáticas, mientras que en Brasil fue mucho más leve.

Las nuevas plantas procesadoras de recursos naturales llevaron a una rápida expansión de las exportaciones, en las cuales la participación de los alimentos, bebidas y tabaco y de los commodities industriales se incremento notablemente: en Argentina, la de estos últimos paś de $12.8 \%$ a $25.3 \%$ entre 1974 y 1990, en Brasil de 7.1 a $35.4 \%$, y en México de 23.8 a $27.8 \%$. En Chile, en cambio, fueron las industrias de alimentos elaborados las que incrementaron su participación de 13.8 a $38.0 \%$.

Los datos nos muestran también que frente al claro éxito de las exportaciones de commodities industriales y alimentos, bebidas y tabaco, hubo un incremento del déficit comercial, en especial por la creciente incapacidad del complejo metalmecánico de competir con las importaciones en el mercado interno. En la práctica, sólo Brasil logró mejorar su balance comercial a partir de 1974 y mantener un superávit hasta 1994. El fuerte incremento de los coeficientes de importación en los demás países confurma este proceso (cuadro 7).

A partir de 1990 se observa un nuevo hecho de interes: el claro resurgimiento - salvo en Chile - de la industrja automotriz.

En efecto, muchas plantas de esa industria han sido recientemente reestructuradas a fondo, en consonancia con un cambio significativo en las estrategias de mercado de las empresas involucradas. De un modelo con un alto grado de integración vertical y de autoaprovisionamiento de partes y piezas y con un esfuerzo considerable de 'ingeniería adaptativa' llevada a cabo en cada establecimiento fabril, se está pasando a fábricas que funcionan con menos integración vertical, más aprovisionamiento externo de partes y subconjuntos, y menores esfuerzos de ingenieria de fábrica. En otros términos, se está avanzando hacia un modelo organizacional más cercano al montaje o ensamblaje de componentes importados que a la fabricacion local integrada.

Junto al fenómeno anterior, también resalta en los casos đe Chile, Argentina y México la contracción de las restantes actividades del área metalmecánica (producción de bienes de capital, maquinaria agrícola, máquinas herramientas, etc.), que tienen bastante valor agregado nacional e ingeniería de planta y un alto impacto en la capacidad tecnológica local. Las activi- 


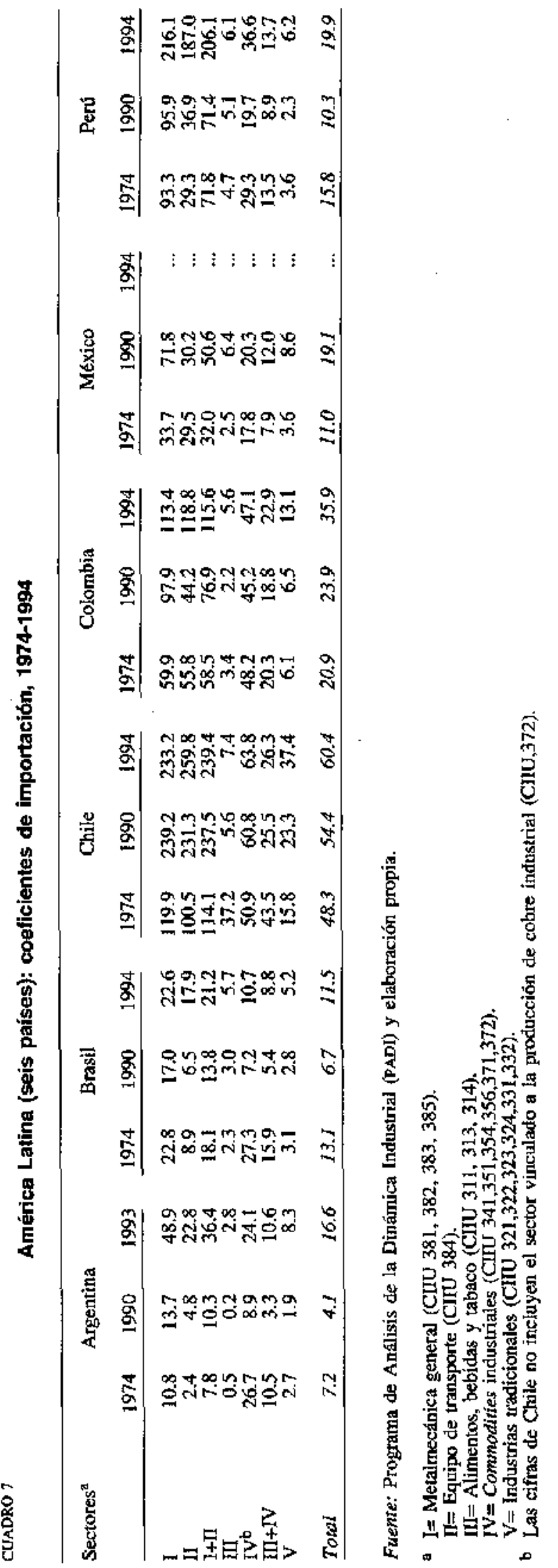

dades de investigación y desarrollo de productos y procesos productivos nuevos han disminuido, $y$ las firmas locales de estas ramas industriales parecen ahora más proclives a operar como representantes y licenciatarios de marcas internacionales que décadas atrás.

En Brasil, la destrucción de la capacidad local de ingeniería parece ser menos dramática que en los otros países mencionados; sin embargo, también en este caso la dirección general del proceso de reestructuración muestra rasgos parecidos.

\section{c) Diferencias entre paises en el desempeño y los resultados}

A pesar de que este movimiento hacia las industrias procesadoras de recursos naturales fue relativamente generalizado en la región, no debe perderse de vista que la forma que adopto este proceso de transformación estructural mostró diferencias entre países, las que son importantes a la hora de evaluar la sustentabilidad a largo plazo del proceso. En efecto, el índice de cambio estructural (ICE) ${ }^{3}$ acusa un valor más elevado para Chile que para México o Brasil, indicando con ello que los cambios de la estructura productiva fueron bastante más radicales en el primer caso. Argentina y Colombia, por su lado, aparecen en una posicion intermedia (cuadro 6).

Brasil logró preservar, en mayor medida que los restantes países considerados, aquellos sectores metalmecánico y de bienes de capital que hacen uso más intensivo de ingeniería nacional y son fuentes muy importantes de desarrollo de la capacidad tecnológica local (cuadro 6). En Chile, en cambio, estos sectores sufrieron un claro retroceso y uno algo menor pero tambiên significativo se dio en Argentina (el único país que al comienzo del período 1974-1994 exhibía un complejo metalmecánico del mismo nivel de desarro1lo que el brasileño). En este sentido parecería que incluso dentro de un proceso de reestructuración con múltiples rasgos comunes asociados a la mayor explotación de los recursos naturales y al retorno a las ventajas comparativas estáticas, han ido creciendo las di-

\footnotetext{
${ }^{3}$ El ICE es un indicador elaborado por la Organización de las Na. ciones Unidas para el Desarrollo Industrial (oNuDi) para medir la imensidad de los cambios en las estructuras industriales. Su calculo se basa en las variaciones del peso relativo de cada sector entre un af́a base y un año final, dentio del valor agregado industrial total de un país. Por lo tanto no mide la dirección de un canbio determínado (es decir, no indica si una estructura evolucionó hacia los commodities industriales o hacia la metalmecinica, sino la dimensión de las modificaciones ocurridas).
} 
ferencias entre los diversos aparatos productivos nacionales, y que Brasil ha preservado más que otros paises de la región su acervo histórico de industrias con alto contenido de ingeniería y sus capacidades tecnológicas acumuladas.

También los indicadores del sector externo ponen de relieve importantes diferencias entre países. Así, el análisis de los coeficientes de importación nos señala algunos puntos de importancia (cuadro 7). Por un lado, en Chile y México los coeficientes de exportación y los de importación experimentaron un fuerte incremento en el curso del periodo indicado, ${ }^{4}$ Por otro lado, Argentina, Brasil y Colombia nos enfrentan con tres situaciones diferentes. En Argentina, el aumento más relevante fue el de los coeficientes de importación; Brasil, en cambio, logró un alza significativa del coeficiente de exportación, sin que sus importaciones aumentaran de manera importante. Y, por último, Colombia alcanzó un incremento algo menor de su capacidad exportadora acompañado de un alza del coeficiente de importaciones, que ya era relativamente alto al comienzo del período considerado. Con todo esto, el balance comercial del sector manufacturero de cada país experimentó suertes diferentes: pas 6 de positivo a negativo en Argentina y Chile, alcanzó un notable superávit en Brasil, y empeoró en Colombia y más aún en México.

Para poder explicar estos comportamientos diferentes hay que tener en cuenta un conjunto de factores estructurales, macroeconómicos e institucionales (véase Bielchowsky y Stumpo, 1996). Es muy probable que el mayor nivel de complejidad alcanzado por los sectores metalmecánicos, el tamaño del mercado interno y un mayor grado de protección mantenido hasta comienzos de los años noventa hayan influido fuertemente en el caso de Brasil para que este país mantuviera una estructura industrial más orientada hacia sectores dinámicos y tecnológicamente avanzados que los otros países de la región.

De la misma manera, en Chile -el caso opuesto- la combinación de una mayor liberalización comercial con una creciente apreciación cambiaria, un mercado interno relativamente pequeño, la ausencia de mercados regionales cercanos de cierta magnitud, la falta de políticas industriales para los productores de bienes de capital y la disponibilidad de abundantes recursos naturales explotables en el corto y mediano plazo, condujo a un proceso de desindustrialización y a que la producción se orientara hacia los commodities industriales basados en recursos naturales.

\section{IV}

\section{Rasgos mesoeconómicos y microeconómicos}

\section{del nuevo escenario de organización industrial}

Hasta aquí hemos examinado el proceso de reestruc turación industrial de América Latina en los años ochenta en un nivel relativamente alto de agregación, mostrando que ha habido un marcado cambio en la composición del producto manufacturero como consecuencia de las políticas de estabilización macroeconómica y de reforma estructural. Las industrias procesadoras de materias primas han alcanzado un exito mayor que aquellas otras que hacen uso intensivo de mano de obra o de servicios de ingeniería y, en consecuen-

\footnotetext{
${ }^{4}$ En realidad también se puede apreciar diferencias entre estos dos países en lo siguiente: mientras Chile orienta su esfuerzo exportador hacia los alimentos y los commodities industriales, México lo hace más bien hacia los autonóviles y los productos electrónicos. Sin embargo, en tos dos casos los principales aumentos de importaciones se concentran en la juetalmecánica.
}

cia, han ganado participación relativa en el producto industrial. Las ramas textil, del calzado y metalmecánica agrupan a las actividades que más han sufrido el impacto de la liberalización comercial y de la desregulación de la economía, y han visto contraerse significativamente su volumen de producción y nivel de empleo. La tasa de mortalidad empresaria en dichos sectores ha sido anormalmente alta, particularmente entre firmas pequeñas y medianas de origen familiar, como veremos a lo largo de esta sección.

Como dijéramos en los párrafos introductorios de este artículo, el proceso de reestructuración socioeconómica de los años ochenta puede examinarse a nivel macroeconómico pero también en un plano mucho más desagregado, atendiendo a los cambios que han ido ocurriendo en la estructura y comportamiento de ramas 
enteras de actividad, $o$ aun en el planeamiento y la organización del trabajo de empresas particulares. Historias de exito y fracaso, de adaptación adecuada o inadecuada al nuevo 'modelo de regulación' de la actividad productiva, pueden ser relatadas en estos diversos planos. Surge entonces la necesidad de que exista coherencia entre la interpretación macro, meso y microeconómica de lo ocurrido durante el proceso de transición al nuevo régimen de políticas públicas de los años noventa. En esta sección nos ocuparemos de la 'lectura' meso y microeconómica de los hechos observados.

A fín de proseguir hacia estos planos más desagregados de análisis económico hemos elegido dos temas particulares en tormo a los cuales presentaremos nuestra argumentación. Primero, los programas de estabilizacion macroeconomica y reforma estructural están lejos de haber sido neutrales en relación a firmas de distinto tipo, lo que se observa al comparar su impacto sobre las pequeñas y medianas empresas de carácter familiar, por un lado, con su efecto sobre los conglomerados de capital local y las subsidiarias locales de empresas transnacionales, por otro. A raíz del sesgo de estos programas en contra de la producción pública y tambiến por su impacto diferenciado sobre el acceso de las empresas a los mercados de factores (particularmente el de capital), los cambios en el régimen global de políticas públicas han sido de hecho un fuerte mecanismo selectivo no neutral que ha favorecido la concentración económica en los países de la región. Segundo, las modificaciones recientes en la organización del trabajo a nivel de planta fabril individual están teniendo un fuerte sesgo ahorrador de mano de obra, lo que está afectando tanto el tamaño como la composición de la fuerza de trabajo empleada. En otros términos, los programas de estabilización macroeconómica y reforma estructural han favorecido la concentración económica y deteriorado la capacidad de las economías de la región para absorber mano de obra en el ámbito de la producción manufacturera. Consideraremos a continuación ambos temas.

\section{El camblante rol de las PYM, las empresas trans- naclonales y los grandes conglomerados de capital local on la producción manufacturera}

Las empresas industriales normalmente pertenecen a uno de cuatro colectivos bien diferenciados: i) las pequeñas y medianas empresas (PYME), muchas de ellas de propiedad familiar; ii) las grandes empresas y los conglomerados de capital local; iii) las subsidiarias locales de empresas transnacionales, $y$ iv) las empresas públicas. Entre estos grupos existen grandes diferencias en los modelos de organización del trabajo, en la densidad de capital, en el acceso a los mercados de factores (particularmente al de capital de largo plazo) y en las capacidades tecnologicas entre otros. Los recientes cambios en el régimen global de políticas públicas están lejos de haber sido neutrales en su impacto sobre estos colectives, lo que ha desencadenado una significativa concentración económica en el ámbito de la producción manufacturera.

Pensemos en el primer grupo, el vasto universo de las PYME, muchas de ellas de estructura y propiedad aún familiar, fuertemente representadas en la producción de bienes como calzado, máquinas herramientas, muebles o vestuario. En todos estos sectores se observo una elevada tasa de mortalidad empresaria en los años ochenta como consecuencia, primero, de la severa contracción de la demanda interna que siguió a los programas de estabilización macroeconómica y, posteriormente, por las dificultades que este grupo de empresas ha tenido para adaptarse a la apertura de la economfa y a un régimen competitivo más riguroso, disciplinado por la competencia externa. A las PYME les ha sido más dif́cil acceder a los mercados de capital por su carencia de garantías bancarias aceptables, y a los mercados de tecnología por su proverbial falta de información. Su percepción de la naturaleza de los cambios en el régimen global de políticas públicas ha sido sumamente imperfecta y también sus esfuerzos de adaptación al nuevo modelo de organización industrial (Mizala, 1992; Boscherini y Yogel, 1996). Por tener como punto de partida procesos productivos y diseños de productos anticuados, así como plantas fabriles que aún mantienen mucho de la organización del trabajo anterior a la reciente revolución de la 'manufactura flexible', y una estructura empresarial y de gestión de corte familiar que ha tenido dificultad para asimilar las complejidades de los principios organizativos de 'justo a tiempo' y de 'calidad total', a muchas de las PYME les ha sido imposible sobrevivir en la atmósfera mucho más competitiva de los años noventa (Castillo, Dini y Maggi, 1996; Kosacoff, 1993). Las adquisiciones y compras de empresas, las fusiones forzadas y una aita tasa de quiebras muestran que en dichas industrias muchas veces hasta la mitad de las empresas se ha visto obligada a abandonar el mercado.

De las que sobrevivieron, muchas lo hicieron simplemente porque modificaron de manera significativa la naturaleza de sus operaciones, dando preeminencia a las actividades financieras y especulativas y aban- 
donando en parte su preocupación por lo ingenieril y productivo (Mizala, 1992). Otros, en cambio, lo lograron transformándose en subcontratistas de grandes firmas transnacionales (Posthuma, 1995) o manteniéndose aislados en pequeños nichos de mercado. S6lo unos pocos to hicieron invirtiendo y mejorando significativamente sus instalaciones y sus capacidades tecnológicas, readiestrando su fuerza de trabajo y cambiando de manera profunda sus principios de gestión y administración empresaria. En los años noventa, las firmas más dinámicas han aumentado las compras de equipos extranjeros y la obtención de licencias internacionales para nuevos productos y procesos productivos, $y$ han ido adoptando gradualmente modalidades de arrendamiento con promesa de compraventa (leasing) u obteniendo franquicias (franchising) otorgadas por grandes cadenas transnacionales.

El segundo grupo, el de los grandes conglomerados de capital nacional involucrados en las industrias procesadoras de recursos naturales (celulosa y papel, aceites vegetales, hierro y acero, productos petroqufmicos) logró, a diferencia de las PYME, un avance espectacular dentro de la escena productiva de la región (Bisang, 1996). En años recientes ha aparecido un gran número de nuevas plantas fabriles con alta densidad de capital y tecnologías muy cercanas a las más avanzadas del ámbito internacional, gran parte de las cuales son de propiedad de estos conglomerados. Ellas han contado con generosos subsidios fiscales y otras formas de apoyo público (Bisang, Burachik y Katz, 1995), especialmente en Argentina y Brasil. Como explicamos en nuestra sección anterior, muchas de estas plantas fueron originalmente pensadas para satisfacer la demanda interna de dichos países, aunque no así en el caso de Chile (Diaz, 1996; Stumpo, 1995); posteriormente ellas debieron reprogramar su estrategia operativa y volcarse a la exportación cuando el mercado interno se contrajo a ralz de los programas de estabilización macroeconómica y la capacidad instalada resultó redundante frente a un mercado interno disminujdo a veces hasta la mitad de lo previsto. En fechas más recientes, muchos de estos grandes conglomerados de capital nacional han establecido acuerdos y alianzas estratégicas con casas bancarias transnacionales y con subcontratistas ofirmas de ingeniería del exterior a fin de participar en los programas de privatización emprendidos como parte de la estrategia global de desarrollo de distintos países de la región; su poder de mercado ha aumentado aún más en la escena prođuctiva local a raíz de estos acuerdos de asociación.
El tercer grupo de empresas que reclama atención es el de las subsidiarias locales de firmas transnacionales, dedicadas principalmente a la fabricación de alimentos, automóviles, productos petroquímicos y medicamentos. El flujo de inversion extranjera directa hacia el sector industrial latinoamericano bajo significativamente en los afios ochenta, época en que diversas firmas transnacionales decidieron dejar los mercados de Argentina, Chile y Colombia - y algo menos el de Brasil- ante la contracción de la demanda interna y el clima de turbulencia económica y social. A fines de ese decenio y principios de los noventa algunas de estas firmas buscaron regresar a dichos países. Este retorno, sin embargo, muchas veces ha sido parte de una estrategia globalizada de funcionamiento transnacional y no ha obedecido ya a la perspectiva de abastecer casi exclusivamente el mercado local de los países receptores. Dados los avances en programas de integración regional como el Mercosur o el Tratado de Libre Comercio de Norteamérica (TLCN o Nafta), esas empresas han dado un carácter más permanente a sus estrategias de operacion globalizada y sus directorios han buscado nuevas formas de organización para adaptarse a ellas. La privatización de activos del sector público y la compra a precios de descarte de los certifícados de la deuda en los mercados secundarios de dichos valores brindaron amplias oportunidades para que empresas transnacionales viejas y nuevas ampliaran sus intereses en la region, aumentando su participación relativa en el PtB.

El cuarto y último grupo es el de las grandes empresas del Estado que han tenido a lo largo de los afos un rol protagónico en la explotación petrolera, la siderurgia, la minería y otros campos. Muchas de estas empresas fueron el eje de los procesos de privatización llevados a cabo en años recientes en la región. En muchos casos tales privatizaciones se efectuaron primordialmente por razones fiscales de corto plazo con el propósito de allegar recursos a las arcas gubernamentales. En otros - quizás los menos- el objetivo fue más bien el de mejorar la eficiencia microeconómica del aparato productivo, saliendo de escenarios de monopolio y buscando, mediante el fraccionamiento de esas empresas, nuevas formas de competencia destinadas a favorecer al usuario final de servicios. Diversos ejemplos de esta indole pueden encontrarse, entre otros campos, en la generación y distribución de energía y en las telecomunicaciones, siendo Chile quizás el país que más ha avanzado en esa dirección. Es difícil efectuar un balance final acerca del 
Exito o fracaso de lo ocurrido en esta materia, pero to cierto es que las grandes firmas estatales han perdido considerable presencia en la región, y su participación relativa en el PB manufacturero y en el global ha caído de manera significativa.

En los años noventa cada uno de estos cuatro grandes grupos empresarios ha debido enfrentar dis. tintos tipos de desaffos y nuevas oportunidades ante el cambio en el régimen global de políticas públicas. $\mathrm{Su}$ capacidad de adaptación al nuevo conjunto de reglas del juego ha sido muy diversa, de modo que sus resultados exhiben notables diferencias. Tanto las empresas pequeñas y medianas, muchas de ellas de propiedad y organización familiar, como las grandes empresas públicas han perdido considerable terreno en la región, lo que ha derivado en un fuerte aumento de la concentración económica tanto sectorial como dentro del conjunto de la actividad económica global de cada sociedad. Así, a mediados de los años noventa el $30 \%$ o más del producto industrial de cada uno de los países de la región está controlado por algo as como una veintena de grandes empresas, ya sea conglomerados de capital nacional o subsidiarias de firmas transnacionales (Paredes y Sánchez, 1996; Bisang, 1996; Obstchatko, 1996).

\section{El sesgo ahorrador de fectores que tienen 108 cambios recientes en la estructura productiva y la organización de la producclón a nivel de la empresa}

El proceso de reestructuración industrial que hasta aquí hemos venido examinando ha tenido lugar en contextos macroeconómicos sumamente inestables y en medio de gran turbulencia social. Uno de los rasgos centrales de dicho proceso ha sido la fuerte contracción de la inversión bruta, tanto privada como pública. Sin embargo, la tasa de inversión en sectores particulares de la industria - por ejemplo, en las ramas procesadoras de recursos naturales-se ha mantenido significativamente alta, incluso cuando ha cafdo la inversión global. Debemos suponer, por lo tanto, que el peso relativo de las ramas productivas que hacen uso intensivo de capital ha aumentado considerablemente dentro de cada economía, en tanto que el de las ramas relativamente intensivas en el uso de mano de obra o de conocimientos tecnológicos y servicios de ingenierfa ha caído de manera significativa.

Las nuevas plantas procesadoras de recursos naturales requieren poca gente. Por lo general son altamente automatizadas, su ritmo de trabajo está dado por los subprocesos básicos empleados y no por la organización del trabajo fabril, el conjunto de bienes que producen es muy estandarizado, no requieren de gran trabajo ingenieril en diseño de productos y prácticamente no utilizan mano de obra de baja calificacion (Obstchatko, 1996).

Por otro lado, la reestructuración del aparato productivo en las ramas industriales que hacen uso intensivo de mano de obra, o de servicios de ingeniería y de organización y métodos de trabajo, como las de calzado, vestuario, textiles, máquinas herramientas y equipos agricolas, ha desembocado en una fuerte reducción del empleo administrativo, así como también de los operarios y técnicos de planta. A medida que las empresas han ido avanzando hacia una menor integración vertical en sus procesos productivos, hacia la subcontratación a terceros de partes, componentes y servicios, y hacia la incorporación de un mayor contenido unitario de importaciones en sus productos finales, el efecto ahorrador de mano de obra ha resultado más visible. Estos procesos llevaron a introducir una infinidad de cambios tecnológicos 'desincorporados' que ahorran mano de obra. Muchas firmas han comprobado que pueden producir el mismo producto, o quizás más, con la mitad o aun un tercio de la mano de obra empleada antes. La productividad laboral ha crecido significativamente, en tanto que el desempleo estructural ha comenzado a ser una preocupación central de diversos países de la región, entre ellos Argentina y Brasil (Katz, ed., 1996). En muchos de los países esto ha ocurrido conjuntamente con un fuerte debilitamiento de la estructura sindical, en el marco de un cambio radical en las relaciones taborales y el conportamiento de las instituciones prototípicas del mercado de trabajo. El despido simplificado y las formas flexibles de contratación han experimentado un fuette avance respecto de una o dos décadas atrás.

Desde una perspectiva general, podemos pensar que los empresarios se agrupan en tres grandes categorlas, según su reacción frente a la reestructuración de sus plantas fabriles y de sus estrategias de largo plazo (Kosacoff, 1993). Están, por un lado, aquellas firmas 'proactivas' en las que la adaptación al nuevo conjunto de reglas del juego ha significado, entre otras cosas, nuevas inversiones físicas, la expansión de la capacidad instalada, cambios en la gama y la naturaleza de los productos fabricados, readiestramiento del personal y cambios en las relaciones sindicales. Además de las industrias procesadosas de recursos naturales, a las que ya hemos hecho mención anteriormente, debemos incluir en este grupo a la industria automo- 
triz, particularmente la de México y en menor medida las de Brasil y Argentina (Shaiken y Mankita, 1995).

Una segunda categorfa, bastante significativa, abarca las empresas que han adoptado una actitud defensiva frente a los hechos y que han concentrado su respuesta en el ahorro relativo de mano de obra mediante la introducción de múltiples cambios tecnológicos 'desincorporados' en la organización del trabajo (Kosacoff, 1996). En esta categoría y en la anterior la relación capital/trabajo ha crecido significativamente - mucho más en la primera que en la segunda- y también lo ha hecho la productividad laboral. El reemplazo de trabajo por capital y los cambios tecnologicos que ahorran mano de obra han desempeñado un papel importante en ambos tipos de situaciones (Katz, ed., 1996).

Existe, sin duda, una tercera categoría de empresas, sumamente significativa en número, cuya adaptación a las nuevas circunstancias ha sido mínima o ni siquiera se ha intentado; en ella la tasa de mortalidad empresaria es y seguirá siendo sumamente elevada. La inercia, la imperfecta información, la dificultad de acceso a los mercados de factores (particularmente al crédito de largo plazo) y de tecnología aparecen como los principales motivos de estas situaciones. Dado el gran número de empresas en esta categoría, es fácil comprender por qué la heterogeneidad estructural ha ido en aumento en los diversos países, y por qué un amplio sector de la comunidad siente que las nuevas políticas macroeconómicas amenazan su supervivencia.

En resumen, en la región ha habido una transición incompleta e imperfecta a un nuevo modelo de organización social de la producción, en el cual la concentración económica es mayor que en el pasado inmediato y en el que se generan pocas nuevas oportunidades de empleo. La productividad laboral ha experimentado avances muy significativos en diversas ramas de la industria, pero la heterogeneidad estructural hace que las mejoras no sean generalizadas ni invoiucren a la totalidad de la fuerza de trabajo. Todo esto está ocurriendo en una estructura industrial que de partida estaba muy rezagada respecto de los estándares internacionales de productividad laboral. Cabe esperar que la dinámica hasta aquí descrita evolucione y que con el tiempo se cierre la brecha relativa que separa a los parses latinoamericanos de la frontera tecnológica internacional. $Y$, si esto sucediera en términos agregados, Łque diferencias entre industrias podrían aparecer? Examinaremos este tema en nuestra próxima sección.

\section{V}

\section{La brecha relativa de productividad}

En esta sección se intenta explorar el tema de la brecha relativa de productividad que separa a la región de la frontera tecnológica internacional.

Una alternativa para estudiar esos procesos de convergencia pasa por formular un modelo de crecimiento estructural y, a partir de él, estimar una versión reducida para las variables exógenas. Este procedimiento, que ha sido típicamente utilizado en los estudios empíricos sobre las llamadas nuevas teorías de crecimiento endógeno, supone que el investigador conoce el 'verdadero modelo' $y$, por ende, que no incurre en sesgos de especificacion.

Otra alternativa es la de examinar el problema a partir del estudio de las propiedades estocásticas de las series de tiempo involucradas, y luego establecer un marco interpretativo para los hallazgos obtenidos; este enfoque tiene la ventaja de que exime al investigador de formular un modelo causal a priori, y además ha mostrado capacidades predictivas superiores a las aproximaciones más convencionales (Dickey y Fuller, 1979; Doornik y Hendry, 1994).

Si se sigue este último camino, luego de estudiar el grado de integración de las series e identificar su proceso estocástico generador, se busca una presentación estacionaria de ellas y mediante sendas estimaciones por mínimos cuadrados recursivos, junto con Tests de Chow secuenciales, se procede a identificar quiebres estructurales tanto en los niveles como en las tendencias de cada serie.

Esta metodología fue la que se aplicó aquí a la productividad laboral de América Latina y de Estados Unidos en los rubros siguientes: total manufacturero; alimentos, bebidas y tabaco; commodities industriales; maquinaria y equipos, e industrias tradicionales. Las pruebas del orden de integración de las series se basaron en Tests de Dickey-Fuller aumentados con rezagos 
variables para cada serie y una tendencia determinística. En ninguno de los casos se pudo rechazar la hipótesis nula de que las series son integradas de orden uno. Se trabajo entonces en términos de tasas de crecimiento de la productividad laboral. Los resultados que surgen de estimar el modelo 1 se presentan en los apartados que siguen.

\section{Modelo 1}

$$
\left.\operatorname{Din}(Q / L)_{i j t}=\alpha+\beta T r e n d+\Sigma^{K}{ }_{h=1} l \gamma_{h} D_{i j h}+\delta_{h}\left(D_{i j h}{ }^{*} \operatorname{Trend}\right)\right]+e_{i j e}
$$

donde:

$i=$ sector.

$j \quad=$ región (América Latina o Estados Unidos).

$D_{\ddot{p h h}}=$ variable muda que toma el valor 0 o 1 según exista evidencia o no de cambio estructural en el período $h$.

$K=$ número de posibles cambios estructurales identificados.

$\boldsymbol{e}_{i j i}=\mathrm{N}\left(0, \sigma^{2}\right)$.

1. ¿Cerrando la brecha o perdiendo terreno reiativo? La experlencla de los ahos setenta, ochenta y noventa

En el grafico 1 se muestran los resultados obtenidos para el total de la industria manufacturera al comparar la productividad laboral de América Latina con la de Estados Unidos entre 1975 y 1995. En el segmento superior izquierdo del gráfico aparecen los logaritmos de la productividad laboral en las dos regiones; en el segmento superior derecho se muestran las mismas series, pero traslapadas de manera de ajustar las medias de las series, simulando de esta manera condiciones iniciales idénticas; finalmente, en el segmento inferior se muestra la evolución de las tasas de crecimiento de la productividad y se identifican las discontinuidades de cada serie.

En términos generales, América Latina tenía hacia 1970 una productividad laboral industrial que era $\tan$ s6lo un $26.5 \%$ de la estadounidense. Se inicio luego un proceso de convergencia que coincidio con la crisis petrolera y con una caída absoluta de la productividad estadounidense que se mantuvo hasta 1983. La región, entre tanto, siguio creciendo a un ritmo cercano al $2 \%$ anual, sin acusar los efectos adversos de la crisis del petróleo; esto es propio de economías cerradas en las cuales el Estado, a través del control de la divisa, actúa para amortiguar la volatilidad de los precios externos, muchas veces financiándose con el impuesto inflacionario.
El proceso de convergencia se detuvo luego, al recuperar Estados Unidos un mayor ritmo de crecimiento a mediados de los años ochenta. $Y$ aunque la región también se recobró un tanto con el aflojamiento de la restricción externa (fruto de la crisis de la deuda) y los cambios estructurales de comienzos de los años noventa, este hecho ha tenido efectos transitorios más que permanentes en la tasa de crecimiento de la productividad latinoamericana: ha habido más bien un salto "de una vez" que acerca el nivel de la region a la frontera internacional pero que no se sostiene en el tiempo. Como resultado, al final del perído 1974-1994 la convergencia era casi insignificante, y la productividad latinoamericana todavía se ubicaba a un $27.2 \%$ de la estadounidense.

\section{Produetividad diferencial por grandes grupos de sectores}

En esta sección se analizan las diferencias sectoriales de productividad laboral entre América Latina y Estados Unidos. El gráfico 2 muestra el comportamiento de las industrias de alimentos, bebidas y tabaco. Según se aprecia, en América Latina este sector exhibe una gran estabilidad (su productividad crece a menos de $2 \%$ anual en 1970-1994). En Estados Unidos en cambio acusa el fuerte impacto de la crisis de mediados de los años setenta, cuando el crecimiento de la productividad se desacelera en seis puntos porcentuales; la situación se revierte de nuevo a partir de 1983, pero a tasas cada vez menores, hasta alcanzar niveles cercanos al 3\% anual hacia 1994. Este patrón permite reproducir un proceso de convergencia similar al de la industria en su conjunto, con una brecha que se cierra a partir de 1974 y que se abre consistentemente a partir de la segunda mitad de los aftos ochenta. Como resultado neto, la productividad latinoamericana en este sector se mantiene estabilizada en un $22 \%$ de la productividad estadounidense.

Por otro lado, el sector de las industrias tradicionales (textil, de vestuario y de calzado) crece a lo largo de 1970-1994 a un ritmo algo inferior al $2 \%$ anual. Sin embargo, a diferencia de lo que sucede con el caso anterior, la productividad de estas industrias a comienzos de la década de 1990 tiene un vuelco positivo que no puede mantener, terminando el período de análisis con una tendencia a la baja. Estados Unidos, en cambio, reacciona a los fuertes efectos de'Ja recesión de los años setenta con una caída de seis puntos porcentuales en la tasa de crecimiento ( $y$ una baja de la productividad); sin embargo, su sector tradicional se te- 
GRAFCO 1

America Latina y Estados Unidos: Productividad Iaboral on el conjunto de la Induatria manufacturera entre 1970 y 1994

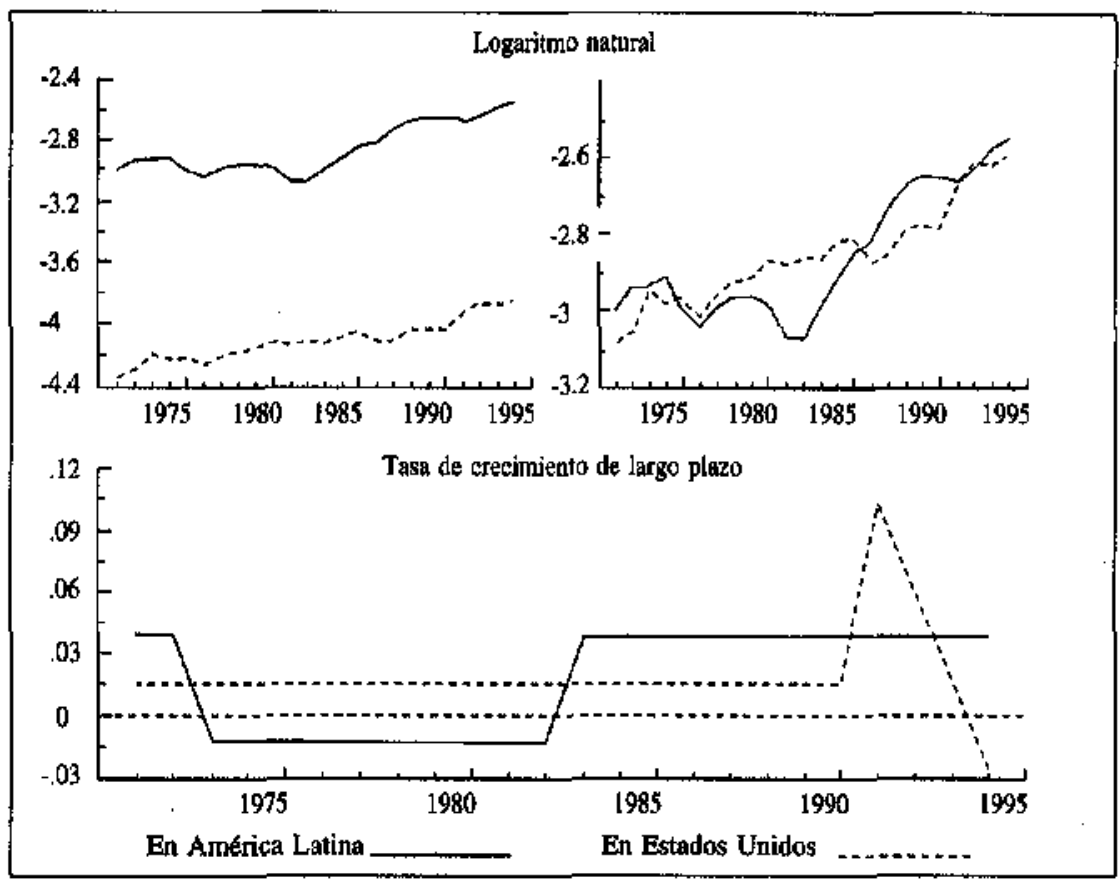

Fuente: Elaboración propia.

GRAFTCO 2

Amórica Latina y Estadios Unidos: Productividad laboral on el sector de allmentos, bebldas y tabaco, entre 1970 y 1994

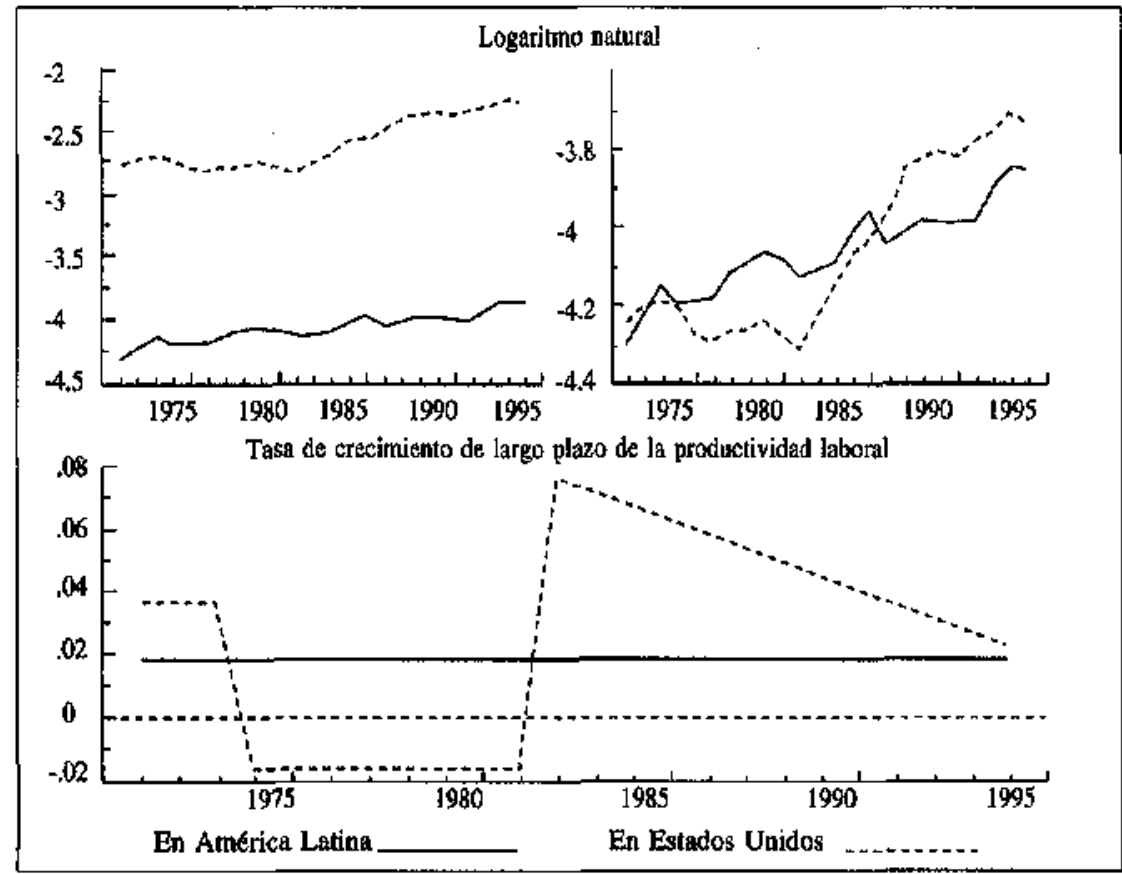

Fuente: Elaboración propia 
GRAFTCO 3 Amórlece Latina y Estados Unldos: Productividad laboral en el sector de las industrias tradicionales, entre 1970 y 1994

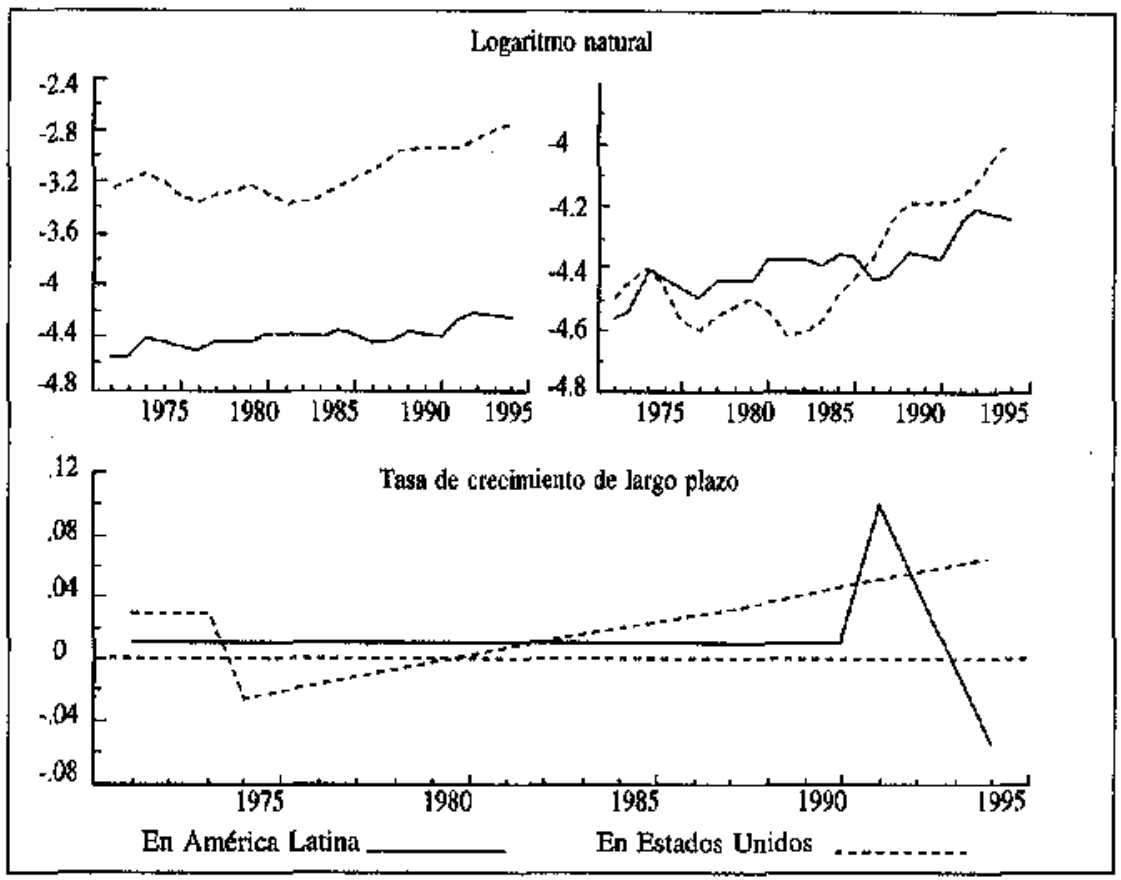

Fuente: Elaboracion propia.

cupera mucho más rápido que las industrias de alimentos, bebidas y tabaco, que permanecen estancadas por mayor tiempo. Esto hace que la convergencia sea mucho menos débil, y que como resultado el sector sufra en América Latina un retroceso relativo frente a Estados Unidos, pasando de una eficiencia relativa ${ }^{5}$ de $27.5 \%$ a una de $22.5 \%$ (gráfico 3 ).

Por lo demás, en el sector de commodities industriales America Latina presenta un comportamiento estable a lo largo de todo el período, y un crecimiento en torno al 3\% anual. Esta tasa es claramente superior a la de Estados Unidos (1.5\% ), lo que permite un proceso consistente de convergencia que se refuerza con la crisis del sector en Estados Unidos desde fines de los años setenta hasta comienzos del decenio de 1980. En este último paŕs el sector se recupera con un vigoroso crecimiento que no logra mantener (tal vez se trata sólo de una recuperación de capacidad subutilizada) y se estanca hacia mediados de los años noventa. En términos netos, la region experimenta un cierre consistente de su brecha relativa, al pasar su eficiencia relativa del $33.3 \%$ en 1970 al $45 \%$ en 1994 (gráfico 4).

5 Entendida como la relación entre la productividad laboral de América Latina y la de Estados Unidos.
Finalmente, en el sector metalmecánico y en el de equipos de transporte la productividad latinoamericana y la estadounidense tienden a converger (gráficos 5 y 6); pero como la brecha inicial es mayor en el caso de los equipos de transporte, la tasa de cierre es más alta en la industria automotriz que en la metalmecánica. Entre los factores que contribuyen al cierre de la brecha está nuevamente el efecto de la crisis de los años setenta, que desacelera el crecimiento de la productividad estadounidense en ocho puntos porcentuales para ambos sectores, mientras que la productividad de la región continúa creciendo a su ritmo histórico de $3 \%$ en la industria de equipos de transporte y de $1.7 \%$ en la metalmecánica. Sin embargo, es en esta última donde se produce un cambio 'permanente' de su productividad en el primer quinquenio de los años noventa, hasta posicionarse por encima de la trayectoria de Estados Unidos lográndose un cierre mayor de la brecha en este sector.

En resumen, al considerar las variaciones de la productividad laboral de distintas actividades industriales tanto de America Latina en su conjunto como de Estados Unidos, se observa que entre 1970 y 1974 ha habido un proceso de convergencia en el sector de commodities industriales y en el de equipos de transporte (sobre todo la rama automotriz). Un paso 
GRÁTCO 4

Amárlea Latina y Estados Unldas: Productivldad laboral en of conjunto de los commodites Industriales, entre 1970 y 1994

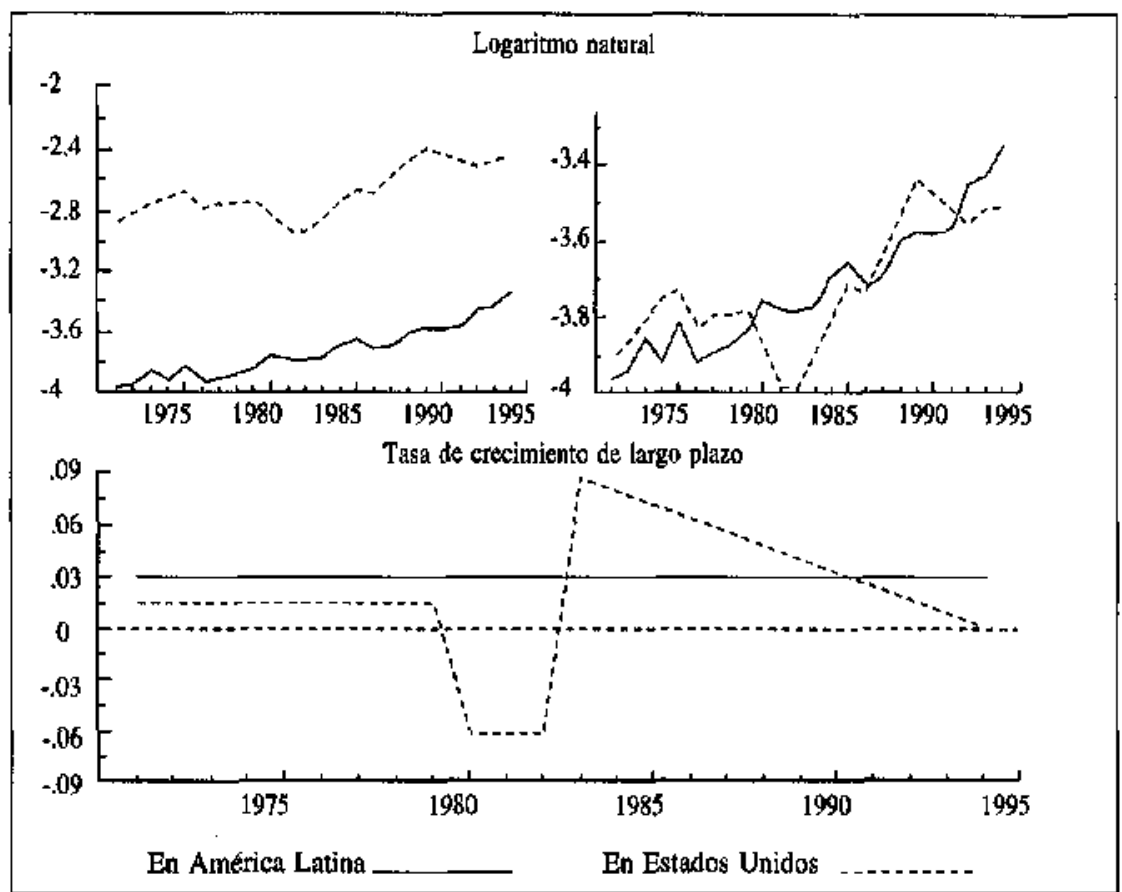

Fuente: Elaboración propia.

GRÁFICO 5

América Latina y Estados Unidos: Productividad laboral en el sector metalmecónico, entre 1970 y 1994

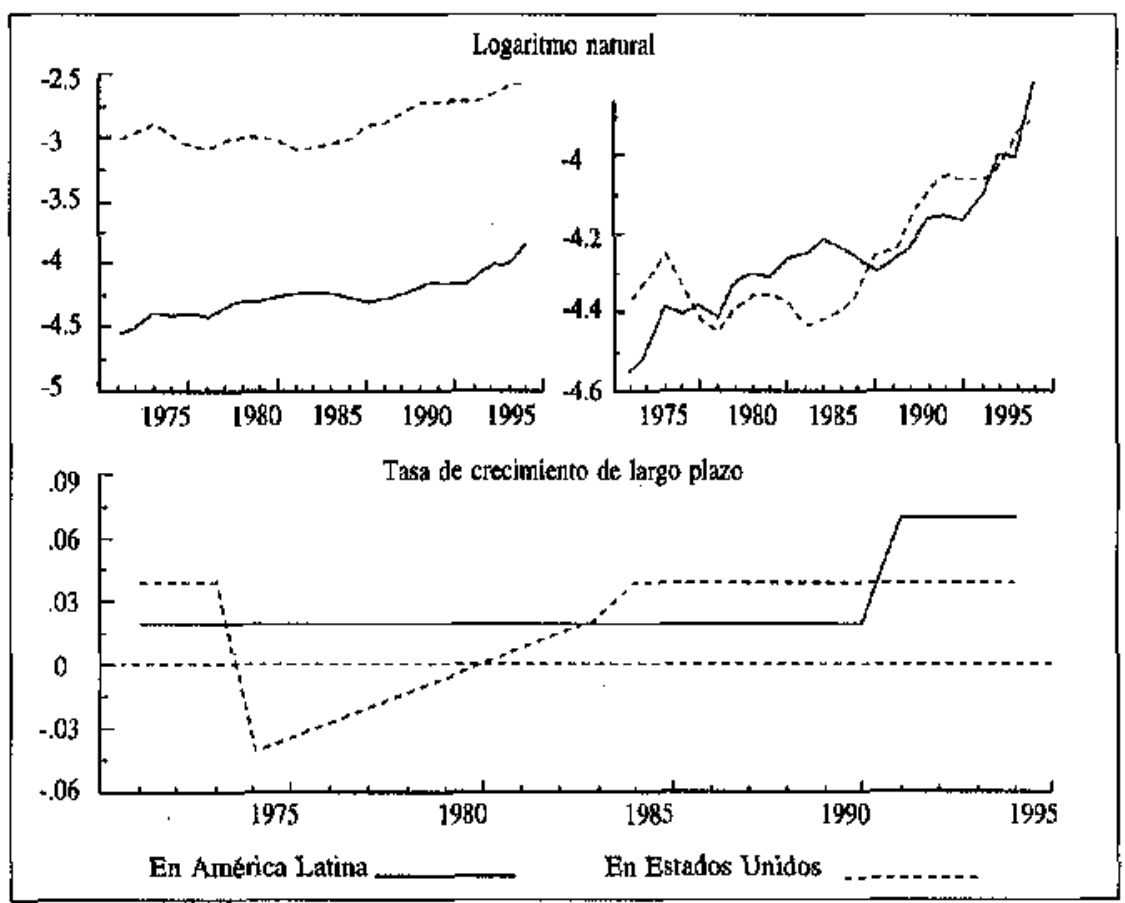

Fuente: Elaboración propia. 
GRAFICO 6

Amórlca Latina y Estados Unidos: Productividad laboral en el sector de aquipos de transporte, ontre 1970 y 1994

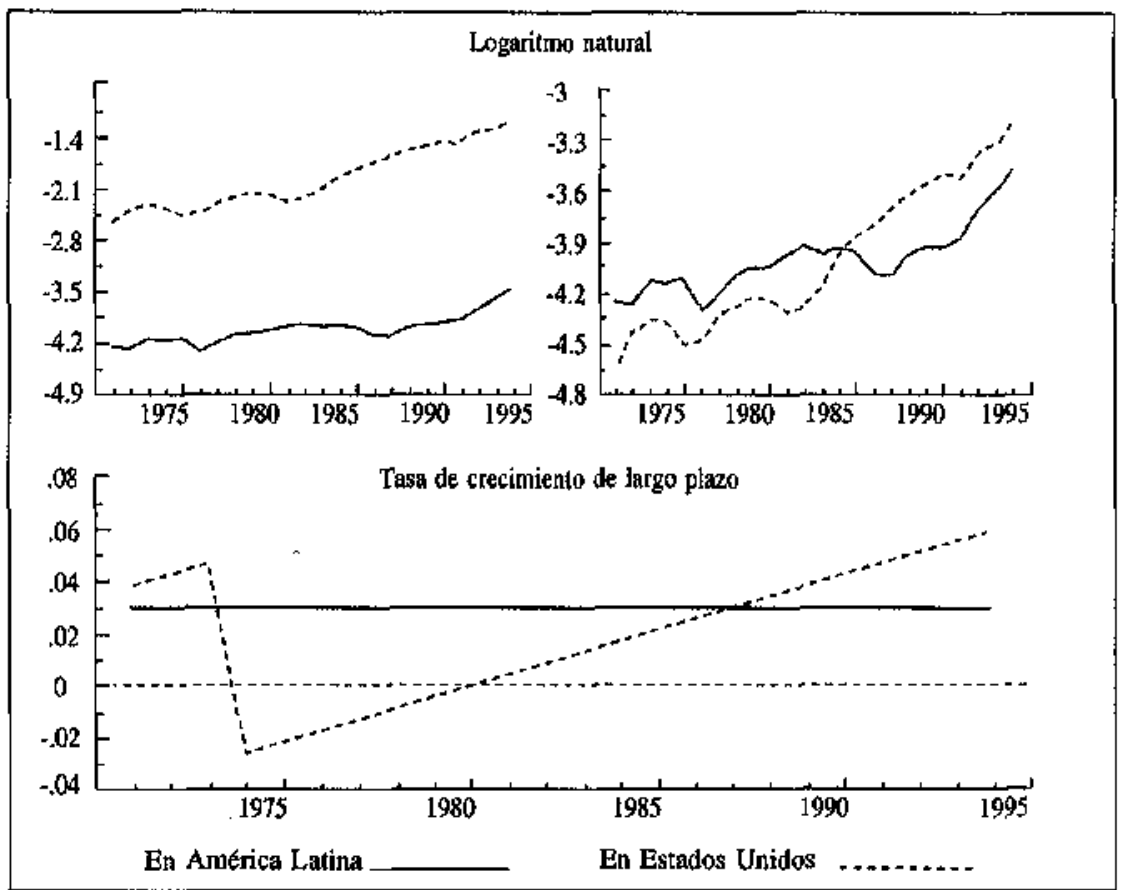

Fuente: Elaboración propia.

más atrás, pero no por ello menos importante, se ubica el sector metalmecánico, el que ha cerrado su brecha relativa en cerca de $28 \%$ (cuadro 8 ).

En contraste con estos 'éxitos', ha habido una pérdida significativa -un ensanchamiento de la brecha- en el sector denominado tradicional. El sector de alimentos, bebidas y tabaco no presenta variación al considerar el período completo.

CUADRO 8

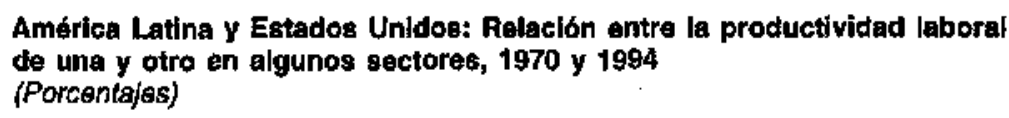

\begin{tabular}{lccc}
\hline Sectores & $\begin{array}{c}\text { Eficiencia inicial } \\
(1970)\end{array}$ & $\begin{array}{c}\text { Eficiencia final } \\
(1994)\end{array}$ & $\begin{array}{c}\text { Variación porcentual } \\
\text { entre } 1970 \text { y } 1994\end{array}$ \\
\hline De alimentos, bebidas y tabacos & 22.3 & 22.3 & $-\overline{8}$ \\
Industrias tradicionales & 27.5 & 22.5 & -18 \\
De commodities industriales & 33.3 & 45.0 & 35 \\
Metalmećnico & 22.3 & 28.6 & 28 \\
De equipos de transporte & 16.5 & 23.4 & 42 \\
\hline
\end{tabular}

Fuente: Elaboración propia. 


\section{Bibliografia}

Bielschowsky, R. y G. Stumpo (1996): Enpresas transnacionales manufactureras en cuatro estilos de reestructuración en América Latina. Argentina, Brasil, Chile y México después de la sustitución de importaciones, J. Katz (ed.), Estabilización macroeconomica, reforma estructural y comportamiento industrial, Sartiago de Chile, Comision Económica para América Latina y el Caribe (CEPAL).

Bisang. R. (1996): Perfil tecno-productivo de los grupos económicos en la República Argentina, J. Katz (ed.), Estabilización macroeconómica, reforma estructural y comportaniento industrial, Santiago de Chite, CEPAL.

Bisang, R., G. Burachik y J, Katz (1995); Hacia un nuevo modelo de organización industrial. El sector manufacturero argentino en los años 1990, Santiago de Chile, CEPAL.

Boscherinj F. y G. Yogel (1996): La capacidad innovativa y el fortalecimiento de la competitividad de las firmas; el caso de las PYMES exportadoras argentinas, Buenos Aires, mimeo.

Castillo M., M. Dini y C. Maggi (1996): Reorganización industrial y estrategias competitivas en Chile, en I, Katz (ed.), Estabilizacion macroeconóntca, reforma estrucrural y comportantiento industial, Buenos Aires, CEPAL/IDRC/ Alianza Editorial.

Dfaz, A. (1996): Chile, la industria en la segunda fase exportadora. Trayectoria historica y desafíos para los noventa. J. Katz (ed.). Estabilizacion macroeconómica, reforma estructural y comportaniento industrial, Santiago de Chile, CEPAL.

Dickey, D. A. $y$ W. Fuller (1979): Distribution of the estimators for autoregressive time series with a unit root, Journal of the American Statistical Assaciation, $\mathrm{N}^{0} 74$, Washington, D.C. American Statistical Association.

Doomik, J.A. y D.F. Hendry (1994): An Interactive Econometric Modelling System, Londres, University of Oxford, Institute of Economics and Statistics/Intenutional Thomson Publishing/ Berkshire House.
Katz, J. (ed.) (1996): Estabilizacion macroeconómica, reforma es. tructural y comporiamiento industrial, Santiago de Chile, CEPAL.

Kosacoff, B. (1993): El desafto de la conpetitividad. La industria argentina en transformación. Buenos Aires, Alianza Editorial, S.A.

(1996): Estrategias empresariales en la transformación industrial argentina, documento de trabajo $\mathrm{N}^{\circ} 67$, Buenos Aires, CEPAL.

Mizala A. (1992): Las reformas economicas de los afios 1970 y la industria manufacturera chilena, Colección Estudios CIEPLAN, $N^{\circ} 35$, Santiago de Chile, Corporación de Investigaciones Económicas para Latinoanderica (CIEPLAN).

Nelson R. (1995): Recent evolutionary theorizing about economic change. The Joumal of Economic Literature, vol. XXXIII, No 1, Nashville, Tennessee, American Economic Association.

Obstchatko, E. (1996); Industrializacion basada en recursos naturales, Santiago de Chile, CEPAL, mimeo.

Paredes, R.y J.M. Sánchez (1996): Grupos económicos y desarroIlo. El caso de Chile, J. Katz (ed.), Estabilización macroeconómica, reforma estructural y comportamiento industrial, Santiago de Chile, CEPAL.

Posthuma, A.C. (1995): Restructuring and changing market conditions in the Brazilian auto components industry, Santiatgo de Chile, CEPAL/Centro Internacional de Investigaciones para el Desarrollo (CitD)

Shaiken H., e I. Mankita (1995): Technology and Work Organization in Latin American Motor Vehicle Industries, LC/R.1517, Santiago de Chile, CEPAL/CID

Stumpo, G. (1995): El sector de celulosa y papel en Chile. Un caso exitoso de reestructuración hacia los commodities industríales, LC/R.1521, Santiago de Chite, CEPAL. 